\title{
Evaporative Cooling of Gas Turbine Exhaust Gas: CFD Simulation, Experimental Verification and Sensitivity Analysis
}

\author{
Mohamed Elbayoumi* $^{*}$ Aly M. Elzahaby ${ }^{\dagger}$, and Mohamed K. Khali ${ }^{\ddagger}$
}

\begin{abstract}
When large amount of gas turbine hot exhaust gas is required to be cooled for reuse in a closed cycle system, the conventional cooling methods will no longer be successful. The great temperature difference, the little space available for cooling, the large speed by which the exhaust gas is expelled, and finally the low exhaust gas pressure represent a great challenge for such a practice. Evaporative cooling is increasingly used as an efficient method to enhance thermal comfort in exhaust gas recirculation. In a water spray system, a cloud of very fine water droplets is produced using pressure nozzles. Analysis of spray penetration and evaporation requires a careful integration of the process conditions such as exhaust gas velocity, nozzle spray pattern, and water flow rate. The droplet size distribution is a critical input to calculations of droplet trajectory, evaporation time, and quenching rate. Computational Fluid Dynamics (CFD) is considered a valuable tool when assessing the potential and performance of evaporative cooling.
\end{abstract}

In this paper, a systematic evaluation of the Lagrangian-Eulerian (LE) approach for evaporative cooling provided by the use of a water spray system with a hollow-cone configuration of two nozzles differs in rate and particle size distribution is presented. The evaluation is based on grid-sensitivity analysis and verified using experimental measurements. The effect of the hot exhaust gas temperature, the cooling water flow rate and nozzle Sauter Mean Diameter (SMD) is also presented. The results show that CFD simulation of evaporation by the LE approach, in spite of its limitations, can accurately predict the evaporation process. Finally, a good matching with the experimental measurements of the cooled exhaust gas temperature is achieved.

Keywords: Evaporative cooling, Computational Fluid Dynamics (CFD), Hollow-cone spray, Sauter Mean Diameter (SMD).

\section{Introduction}

Recycling a certain amount of exhaust gas to the engine intake becomes so important practice in such cases where there is a shortage of the amount of Oxygen supplied to the engines and to derive otherwise wasted energy from the exhaust products. This practice is almost used in submarines to increase its range and submerged-time which are the primary goals for ship designers. The recycling process requires cooling the hot exhaust gas, flue gas, which is a mixture of Oxygen, Carbon dioxide, water vapor and Nitrogen at first and then absorbing its

\footnotetext{
*Egyptian Armed Forces. mohamedbemos@gmail.com

†Professor, Tanta University, Tanta, Egypt. elzahaby47@gmail.com .

\$Egyptian Armed Forces. khilo99@yahoo.com .
} 
Carbon dioxide content before mixing it with the pre-stored Oxygen which is used to compensate the amount used in combustion. Many general difficulties have faced the process of recycling the exhaust products. Among these difficulties the excessive cost, need for frequent adjustment, complexity of construction, bulkiness and adverse effect on engine performance. For gas turbines, the indicated practice still has a lack of knowledge due to its exhaust gas different nature as it is expelled with a very high temperature, rate, speed and relatively low pressure. Special attention must be paid when reconditioning these complex attributes.

The hot exhaust gas rapid cooling, quenching, is considered the first stage of the gas turbine exhaust gas recycling process and is known as evaporative cooling. This method is relatively efficient and requires very little space compared to the other conventional cooling ones, [1]. The bulk of the energy from gas cooling is absorbed in vaporizing the quench liquid. The rate of evaporation depends on heat and mass transfer, the drop surface area and relative motion of drops in the gas, [2]. The complex two-phase flow in a water spray system is influenced by many factors such as continuous phase velocity, temperature and relative humidity patterns, droplet characteristics and droplet-droplet interactions, [3].

For assessing the potential and performance of evaporative cooling by water spray systems, different methods can be used: experimental measurements and numerical simulation with Computational Fluid Dynamics (CFD). Experimental measurements offer the advantage that the real situation is studied and the full complexity of the problem is taken into account. However, experimental measurements are usually only performed in a limited number of points in space. In addition, there is no or limited control over the boundary conditions. CFD on the other hand provides whole flow field data, i.e. data on the relevant parameters in all points of the computational domain. CFD simulations easily allow parametric studies to evaluate alternative design configurations. However, the accuracy and reliability of CFD are of concern, and verification studies are imperative. The Lagrangian-Eulerian (LE) approach has been used in which the continuous phase (hot gas in this study) is represented in an Eulerian reference frame while the discrete phase (water droplets in this study) is represented in a Lagrangian reference frame, [4].

A systematic evaluation of the LE approach, using 3D steady Reynolds Averaged NavierStokes (RANS), for predicting evaporative cooling performance provided by a co-current water spray system with a hollow-cone nozzle is presented. The evaluation is based on gridsensitivity analysis and on verification with experimental measurements. The impact of the temperature for the continuous phase and the cooling water rate and nozzle Sauter Mean Diameter (SMD) for the discrete phase is also demonstrated. The results of this paper are intended to support future development of air independent gas turbine engines.

\section{Theoretical Study}

Since the evaporation of water requires a large amount of heat, the gas turbine hot exhaust gas can be cooled simply by spraying water in it. Only the used amount of water is needed to maintain the desired temperature of the gas, [5]. The amount of water that needs to be added in order to cool a certain amount of flue gas down could be simply derived by balancing the enthalpy. Therefore it is assumed that the process is adiabatic and no heat is transferred through the walls of the cooling system, [6]. Equation (1) determines the water spray rate required for evaporation, $\dot{\mathrm{m}}_{\text {spray }}$ 


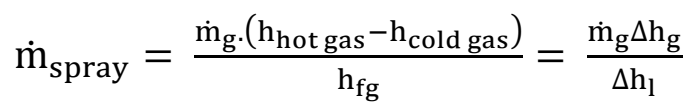

Knowing that: hot exhaust gas flow rate, $\dot{\mathrm{m}}_{\mathrm{g}}$, is $0.14 \mathrm{~kg} / \mathrm{s}$, which is the SPT-5 micro TPE mass flow rate, enthalpy of hot gas, $\mathrm{h}_{\text {hot gas }}$, at $730{ }^{\circ} \mathrm{C}$ is $1060.89 \mathrm{~kJ} / \mathrm{kg}$, enthalpy of cooled gas, $\mathrm{h}_{\text {cold gas }}$, at $50{ }^{\circ} \mathrm{C}$ is $323.45 \mathrm{~kJ} / \mathrm{kg}$ and the difference of the specific enthalpy of the spray, $\Delta \mathrm{h}_{\mathrm{l}}$, contains the specific latent heat due to the phase change of the sprayed liquid, $\mathrm{h}_{\mathrm{fg}}$, for water equals $2263.073 \mathrm{~kJ} / \mathrm{kg}$. Then, the water spray rate required for evaporation, $\dot{\mathrm{m}}_{\text {spray }}$ is $0.045 \mathrm{~kg}_{\mathrm{w}} / \mathrm{s}$.

The calculated amount of water required to cool the gas is only the water that must be evaporated and since all water sprayed in the quench chamber does not evaporate, the pump and spray system should be sized to supply more water than that calculated. The amount of excess water needed depends on many factors such as the inlet temperature of the gas, the temperature drop required, the fineness of the water spray and the arrangement of spray nozzles. It is recommended that the actual water flow rate, $\dot{\mathrm{m}}_{\mathrm{w}}$ supplied by the pump should be at least (2-5) times the water spray rate required for evaporation, [7].

$$
\dot{\mathrm{m}}_{\mathrm{w}}=(2-5) * \dot{\mathrm{m}}_{\text {spray }}
$$

Assuming the exhaust gas has the same properties as the air, the enthalpies of the different gaseous constituents in the exhaust gas stream will show insignificant refinement to the calculations when considered, [8]. Usually the composition of the components of the exhaust gas is given in volume-per-volume percent. Equation (3) determines the mass fraction, $\mathrm{Y}_{\mathrm{i}}$, considering the molecular weight, $\mathrm{M}_{\mathrm{i}}$, of each component and the volume fraction, $\mathrm{X}_{\mathrm{i}}$.

$$
Y_{i}=\frac{M_{i}}{\sum_{i=1}^{n} X_{i} \cdot M_{i}}
$$

The above relations predict reliable results for the gas outlet temperature and composition considering the assumption that the gas phase moves with constant speed throughout the whole quench chamber and there is no slip between the droplets and the gas, i.e. the droplets move with same velocity as the gas phase, [9]. Equation (4) determines the gas phase velocity, $V_{g}$, by applying continuity equation inside the quench chamber. Considering the hot exhaust gas mass flow rate, gas density, $\rho_{\mathrm{g}}$, and area of the quench chamber, $A_{q c}$, the exhaust gas velocity inside the quench chamber is $3.15 \mathrm{~m} / \mathrm{s}$. This value matches the recommended ones for efficient evaporation of water in hot gas stream.

$$
\dot{\mathrm{m}}_{\mathrm{g}}=\rho_{\mathrm{g}} * V_{g} * A_{q c}
$$

The residence time for the largest drop in the spray to evaporate, $\theta$, can be calculated according to Equation (5), [10]. Drop evaporation rate is proportional to the square of the drop size, $\mathrm{D}_{0}$, and inversely proportional to the temperature difference, $\Delta \mathrm{T}$, as shown in Fig. 1 . The evaporation time plays an important role when designing the quench chamber as it will determine the range of the quench chamber length. Considering the assumed no slip condition, a particle will take a certain time, t, to pass through the quench chamber length. For the above velocity and $1 \mathrm{~m}$ quench chamber length, the time required for a particle to pass through the quench chamber reaches $0.3 \mathrm{~s}$. Both of the pass and evaporation times should be matched.

$$
\theta=\frac{\rho_{1} \lambda \mathrm{D}_{0}{ }^{2}}{8 \mathrm{~K}_{\mathrm{g}} \Delta \mathrm{T}}
$$

where

$\rho_{l}$ : Cooling liquid density $\mathrm{kg}$ : Air thermal conductivity $\lambda$ : Cooling liquid heat of vaporization

$\mathrm{T}$ : Log mean temperature difference 
Since all particles of a certain nozzle are not having the same diameter and also the temperature difference varies along the quench chamber length, and considering the dimensions of the nozzle cone pattern (cone coverage diameter and cone length), the complexity of a quench chamber design appears obviously.

\section{Experimental Work}

\subsection{Cooling System Components}

\subsubsection{Quench chamber}

The used cooling system is vertical, down-flow, co-current spray, wet-wall and with quench zone having a larger diameter than inlet piping system. The quench chamber is a cylindrical steel vessel $1.0 \mathrm{~m}$ in height and $0.4 \mathrm{~m}$ in diameter. The inlet and outlet piping are 2 " in diameter at first, and then they are changed to 4". Fig. 2 a. and b. show the first and final quench chamber. The hot gas enters the quench chamber through flexible stainless steel connections $1.0 \mathrm{~m}$ in length and $2 "$ in diameter fitted on the two engine exit nozzles and connected to a 4" T-junction through a 2"- 4" steel adaptor. The cooled gas leaves the quench chamber through a 4" steel exit elbow. The excess water leaves the quench chamber through a 2 " drain hole.

\subsubsection{Spray nozzle}

The selection and sizing of spray nozzles are the most critical decisions in the system design. The position and direction of the nozzles should consider recirculation zones in the placement of quench nozzles to prevent spray contacting the wall, [11]. For this study, two "BETE" P120 and P80 hollow cone direct pressure nozzles are used, Fig. 3 a. shows it. For the first nozzle, P120, the water emerges from a wide thin orifice $3.05 \mathrm{~mm}$ diameter in a laminar jet impinges on target pin generating fine fog. The nozzle cone angle is $90^{\circ}$ for operating pressure above 4 bar. The fog pattern is $1500 \mathrm{~mm}$ coverage diameter and $750 \mathrm{~mm}$ length, as shown in Fig. 3 b. The maximum nozzle flow rate is $151 / \mathrm{min}(0.116 \mathrm{~kg} / \mathrm{s})$ at $8 \mathrm{bar}$. The droplet size distribution varies at this pressure from 120 to 300 microns as shown in Fig. 4 a. The nozzle Sauter mean diameter, $\mathrm{D}_{32}$, is 190 microns.

For the second one, P80, the orifice diameter is $2.03 \mathrm{~mm}$ with the same cone angel. Its fog pattern is $1200 \mathrm{~mm}$ coverage diameter and $600 \mathrm{~mm}$ length. The nozzle maximum flow rate is $7 \mathrm{l} / \mathrm{min}(0.25 \mathrm{~kg} / \mathrm{s})$ at $8 \mathrm{bar}$. The droplet size distribution varies at this pressure from 100 to 200 microns as shown in Fig. 4 b. Steel by "BETE" company, USA.

\subsubsection{Water pump}

Water spray pressures generally range from 3.5-10.5 bar, however, to reduce the amount of moisture collected some installation have employed that pressures should be in the range of 58 bar, [12]. For this study, a Speroni CAM198 single-phase water pump is used, Fig. 5 a. Its water flow rate is $10 \mathrm{l} / \mathrm{min}$ at 5.6 bar as clear from its characteristic curve shown in Fig. 5 b. It could reach 8 bar as a maximum pressure. Its input power is $1 \mathrm{~kW}$.

The system pump-nozzle is tested separately without the quench chamber in order to assure its proper operation and to identify the nozzle fog pattern. A T-connection with $1 / 2$ " diameter is mounted on the pump outline with one side mounted pressure gauge to measure the pump outlet pressure. On the other side, the nozzle is connected to the $1 / 2$ " tube through a 1/2" elbow and a 1/2"-1/4" adaptor. Both of the two nozzles (P80 and P120) are tested individually. Fig. 6 a. shows the pump-nozzle installation while Fig. 6 b. shows the tested nozzle fog pattern for the P120 nozzle. 


\subsection{Measurements}

First, the Jetcat SPT-5 hot EGT and RPM are measured before connecting the cooling system through a temperature sensor, built-in thermocouple located at the engine exit nozzle as shown in Fig. 7 a., and a speed sensor respectively, provided with the engine. A Ground Support Unit (GSU) is connected to the Electric Control Unit (ECU) for monitoring such parameters, Fig. 8.

Second, the cooled EGT is measured after connecting the cooling system with the P120 nozzle at three engine RPMs (120000, 140000, and 165000) through an Omega K-Type thermocouple fixed in the center of the quench chamber exit elbow, Fig. 7 b. The temperature readings are taken at the pump maximum water flow rate and at variable flow rates to demonstrate the change of the cooled exhaust gas temperature with the pump water flow rate.

For all the second exhaust gas temperature measurement system, a pressure gauge is mounted on the pump outlet in order to measure its output pressure, Fig. 9 a. An Omega FTP 101 turbine flow meter is also mounted on the pump outlet line to measure the system water flow rate, Fig. 9 b. The values of the cooled exhaust gas and water flow rate are both stored and monitored using a Lab view interface as shown in Fig. 10. A view of the complete test rig including the cooling system and the measurement instrumentation is shown in Fig. 11.

\section{CFD Simulation}

\subsection{Fundamentals of Simulation}

The CFD simulation in this paper has three objectives:

- Estimating the pressure drop inside the complete cooling system (flexible tubes and the quench chamber) and minimizing it to assure that the low pressure exhaust gas could pass through the cooling system.

- Estimating the total temperature difference between the hot and cooled exhaust gas to evaluate the evaporative cooling performance for the two nozzles.

- Estimating the cooled exhaust gas composition to assure the increase of the cooled exhaust gas water vapor content.

In the commercial software ANSYS/Fluent 16, the Discrete Phase Model (DPM) is used to simulate the two-phase flow problem considering the following assumptions:

- The spray is assumed to be dilute (volume fraction of the dispersed phase is less than $10 \%)$.

- For dilute spray, the average inter-particle distance is around twice the particle diameter. Thus, collisions and interactions among particles can be neglected, [13].

- Two way coupling sub model is considered (particles and continuous flow interact with each other, i.e. particles can exchange heat, mass and momentum with air).

\subsection{Computational Geometry and Grid Generation}

A 3D model for the complete cooling system starting from the engine exit nozzle -including the quench chamber - till the cooled exhaust gas exit elbow is created using Solidworks software and a grid is generated using two different mesh software programs (ANSYS Mesh and Pointwise) to assure its accuracy and solution independence. ANSYS Mesh is used for the final model because of its simplicity and accepted accuracy. The generated grid has $1,407,374$ tetrahedral cells with 354,003 nodes. The maximum aspect ratio is $3.2 * 10^{1}$. The minimum, maximum, and total cell volumes in the domain are approximately $2.066 * 10^{-10}$, $2.618^{*} 10^{-7}$, and $1.356^{*} 10^{-1}$ respectively. A standard wall function with no slip conditions is applied. Fig. 12 a. and b. show the 3D CAD drawing and computational grid of the used model. 


\subsection{Boundary conditions}

The simulation is performed for steady state operation. The mass flow inlet - pressure outlet boundary condition is selected for the continuous phase based on the actual SPT-5 micro TPE mass flow rate $(0.14 \mathrm{~kg} / \mathrm{s})$. Zero static gauge pressure is applied at the outlet. A turbulent intensity, I, of 5\% is assumed for the inlet flow. The turbulent kinetic energy, $\mathrm{K}$, is calculated from $\mathrm{U}_{\infty}$ and I using Equation (6). The turbulence dissipation rate, $\varepsilon$, is given by Equation (7) where $\mathrm{C}_{\mu}$ is a constant $(\sim 0.09)$. The turbulence length scale, $\mathrm{L}$, in this equation is taken as $\mathrm{L}=$ $0.07 \mathrm{D}_{\mathrm{H}}$ where $\mathrm{D}_{\mathrm{H}}$ is the hydraulic diameter of the domain which is equal to the diameter of the quench chamber $(0.4 \mathrm{~m})$.

$$
\begin{gathered}
\mathrm{K}=\frac{3}{2}\left(\mathrm{U}_{\infty} \cdot \mathrm{I}\right)^{2} \\
\varepsilon=\mathrm{C}_{\mu} \frac{3}{4} \frac{\mathrm{K}^{\frac{3}{2}}}{\mathrm{~L}}
\end{gathered}
$$

The thermal boundary condition at the inlet has a constant temperature $(1000 \mathrm{~K}, 883 \mathrm{~K}$, and $823 \mathrm{~K}$ ) representing the last three measured EGTs at engine exit nozzle at different engine regimes. The exhaust gas components (named "Species" in ANSYS Fluent) boundary condition have fixed mass fraction for $\mathrm{CO}_{2}, \mathrm{H}_{2} \mathrm{O}$ and $\mathrm{O}_{2}$ as $0.08,0.04$, and 0.14 respectively. These values are selected based on the analytical calculations of engine combustion equations and the experimental measurements of the different exhaust gas components.

The walls of the computational domain are modelled as no-slip walls with zero roughness height $\mathrm{k}_{\mathrm{s}}=0$. The standard wall functions are applied. The adiabatic thermal boundary condition is used for these surfaces at first to assure that water flow rate is able to achieve the required cooling as driven before from the theoretical calculations. After that, it is changed to the "Convective" one with convective heat transfer coefficient of $10 \mathrm{~W} / \mathrm{m}^{2} . \mathrm{K}$. This value is selected based on the calculations of convective heart transfer coefficient of vertical cylinders, [14]. The heat transferred through walls by conduction is considered using chamber wall thickness as $0.01 \mathrm{~m}$ made of steel. The radiation effect is neglected due to its low contribution.

Special attention is needed for the discrete phase boundary conditions to simulate the real case accurately. The quench chamber is divided into four zones (hot gas inlet, cooled gas outlet, wall and water exit). The "reflected" DPM boundary condition is selected for wall zones only, while the "escape" one is selected for the other zones.

\subsection{Droplet Characteristics}

Geometric properties of droplets in a spray system are one of the most important factors that affect not only the dynamic behavior of the droplets, but also the heat and mass transfer rates between the continuous and discrete phase, [15]. These geometric properties include size and shape of the droplets. The droplet size distribution can be modelled in different ways such as the semi-empirical methods where Rosin-Rammler is applied, [16]. The values of the smallest, largest, and mean droplet diameters for the P120 nozzle are 120, 300, and $190 \mu \mathrm{m}$ while they are 100,200 , and $150 \mu \mathrm{m}$ for the P80 one.

The spherical drag law is used to estimate the drag coefficient acting on droplets. It assumes that the surface tension on the drop-fluid interface is strong enough to resist the tendency of the aerodynamic force to deform the drop (We $<<1)$, [17]. Droplets are assumed to be nondeforming spheres and drag coefficients $\left(\mathrm{C}_{\mathrm{d}}\right)$, as functions of the Reynolds number $(\mathrm{Re})$, are estimated based on experimental drag data for solid spheres by Morsi and Alexander, [18]. Equation 8 shows the used correlation where $\mathrm{a}_{1}, \mathrm{a}_{2}$, and $\mathrm{a}_{3}$ are empirically fitted constants. 


$$
C_{D}=a_{1}+\frac{a_{2}}{R e}+\frac{a_{3}}{\operatorname{Re}^{2}}
$$

\subsection{Spray Nozzle Characteristics}

The hollow cone spray model provided by ANSYS/Fluent 16 is used, [19]. The water droplets are injected into the middle of the quenching chamber from an orifice diameter of 3.05 and $2.03 \mathrm{~mm}$ for the P120 and P80, respectively and oriented vertically in same direction of the hot exhaust gas. The half cone angle for the two nozzles is $45^{\circ}$. The gas velocity is $3.15 \mathrm{~m} / \mathrm{s}$ driven before using 1D mean streamline approximation. The total water mass flow rates are 0.25 and $0.12 \mathrm{~kg} / \mathrm{s}$ corresponds to the maximum P120 and P80 nozzles measured water flow rate. The pure water feed temperature is set at $300 \mathrm{~K}$.

\subsection{Solver Settings}

Gas flow in quench chambers is usually turbulent. Oakley showed that standard k-epsilon $(\mathrm{Sk}-\varepsilon)$ model may be used to simulate the turbulent flow in it when gas flow at inlet has small or no swirling component, [20]. Other turbulence models such as the realizable k- $\varepsilon$ model, the RNG k- $\varepsilon$ model and the Reynolds Stress Model (RSM) are also available. In this paper, the 3D steady RANS equations for conservation of mass, momentum and energy are solved in combination with the standard k- $\varepsilon$ turbulence model for the continuous phase flow. It showed better convergence history and more accurate estimation for the pressure drop and temperature difference through the cooling system when compared with the results of the experimental data. The SIMPLE algorithm is used for pressure-velocity coupling.

Lagrangian trajectory simulation is performed for the discrete phase. The closer coupling strategy between dispersed and continuous flow is used in which the discrete phase interacted with the continuous phase, and the discrete phase model source terms are updated after two continuous phase iterations.

The solution procedures are carried out into two steps. In the first step, the single continuous phase flow without droplets is computed considering the adiabatic thermal assumption for the cooling system walls until its convergence. Then, the computations with the discrete phase are performed.

For distinguishing the temperature difference between the hot and cooled exhaust gas either through natural convection and conduction or evaporative cooling, each of the discrete phase and the walls "Convective" heat transfer assumption is performed separately at first and then they are merged together to simulate the real case.

\subsection{Sensitivity Analysis}

To analyze the sensitivity of the results to various computational and design parameters, systematic changes are made to a reference case. In every sub-section, one of the computational and design parameters is varied, while all others are kept identical to those in the reference case. Due to the complexity of an efficient evaporative cooling system design considering all the previously stated parameters, many cases are performed.

In ANSYS Fluent, the number of droplet streams is the number of locations along the nozzle perimeter where the parcels are injected into the computational domain. Although the injected droplet flow rate is independent of the number of streams, the less droplet streams the lower the computational time that is required. However, a sufficiently large number of streams need to be employed to ensure the accuracy of the results. For this study, approximately 20 streams are considered sufficient for CFD results. 


\section{Results and Discussion}

\subsection{Experimental Measurement Results}

The values of the engine hot and cooled EGT by the P120 nozzle with the engine RPM are listed in Table 1. The variation of the hot EGT with the engine RPM is demonstrated through Fig. 13. It is clear that, the hot EGT has the same profile of the engine RPM. The hot EGT has almost the same value for engine RPM varies between 50000 and 100000 which is $500{ }^{\circ} \mathrm{C}$. The maximum EGT is $730{ }^{\circ} \mathrm{C}$ at the maximum engine RPM 165000.

Table 1. Engine hot and cooled EGT vs RPM measurement results

\begin{tabular}{l|l|l|l|l}
\hline \hline \multirow{2}{*}{ No. } & \multirow{2}{*}{ Engine RPM } & \multicolumn{2}{|l|}{ Engine EGT $\left({ }^{\circ} \mathrm{C}\right)$} & \multirow{2}{*}{$\Delta$} \\
\cline { 3 - 4 } & & Hot & Cooled/P120 & \\
\hline \hline 1 & $50000-100000$ & $480-500$ & - & - \\
\hline 2 & 120000 & 550 & 50 & 500 \\
\hline 3 & 140000 & 610 & 53 & 557 \\
\hline 4 & 165000 & 730 & 64 & 666 \\
\hline \hline
\end{tabular}

The profile of the cooled EGT with the cooling water flow rate at 120000, 140000, and 165000 engine RPMs is demonstrated through Fig. 14 a., b., and c. respectively, for the P120 nozzle. It is clear that the hot EGT at these engine RPMs is cooled to 50, 53, and $64{ }^{\circ} \mathrm{C}$ respectively for the maximum water flow rate $(\approx 15 \mathrm{~L} / \mathrm{min})$.

\subsection{CFD Simulation Results}

The values of the cooled EGT (taking natural convection, conduction effects and expansion inside quench chamber) are listed in Table 2. The cooled exhaust gas water vapor mass ratio, mass flow rate and total pressure drop across the cooling system are also demonstrated in the same table. For the last case (165000 RPM and $730{ }^{\circ} \mathrm{C}$ EGT), the cooled EGT, water vapor mass ratio and quench chamber pressure drop distributions across the complete cooling system are shown in Fig. 15 a., Fig. 16 a., and Fig. 17 a. The same parameters distribution is demonstrated through a mid-half plane inside the quenching chamber as shown in Fig. 15 b., Fig. 16 b., and Fig. 17 b. The temperature distribution across the quench chamber exit elbow is demonstrated in Fig. 18.

The evaporative cooling performance evaluation based on the contribution of the sensible and latent heat in the total hot exhaust gas cooling taking into consideration the water temperature difference is illustrated for each case in Table 3 .

Table 2. CFD simulation results summary

\begin{tabular}{|c|c|c|c|c|c|c|c|}
\hline \multirow[t]{2}{*}{ No. } & \multirow{2}{*}{$\begin{array}{l}\text { Nozzle/ } \\
\text { water rate } \\
(\mathrm{kg} / \mathrm{s})\end{array}$} & \multirow[t]{2}{*}{ RPM } & \multirow[t]{2}{*}{$\begin{array}{l}\text { Cooled EGT } \\
\left({ }^{\circ} \mathrm{C}\right)\end{array}$} & \multirow[t]{2}{*}{$\begin{array}{l}\text { Pressure } \\
\text { drop }(\mathrm{Pa})\end{array}$} & \multirow[t]{2}{*}{$\begin{array}{l}\mathrm{H}_{2} \mathrm{O} \text { mass } \\
\text { ratio }\end{array}$} & \multicolumn{2}{|c|}{$\begin{array}{l}\text { Exit exhaust } \\
\text { gas mass flow } \\
\text { rate }(\mathrm{kg} / \mathrm{s})\end{array}$} \\
\hline & & & & & & $\mathrm{m}_{\mathrm{g}}$ & $\Delta \mathrm{m}_{\mathrm{g}}$ \\
\hline 1 & \multirow{3}{*}{$\begin{array}{l}\mathrm{P} 120 / \\
0.25\end{array}$} & 120000 & 57 & 3429 & 0.122 & 0.158 & 0.018 \\
\hline 2 & & 140000 & 60 & 3643 & 0.153 & 0.160 & 0.020 \\
\hline 3 & & 165000 & 70 & 4197 & 0.171 & 0.166 & 0.026 \\
\hline 4 & P80/0.12 & 120000 & 81 & 3355 & 0.141 & 0.164 & 0.024 \\
\hline
\end{tabular}


Table 3. Evaporative cooling performance evaluation

\begin{tabular}{|c|c|c|c|c|c|c|c|c|c|c|c|}
\hline \multirow{3}{*}{ No } & \multirow{3}{*}{$\begin{array}{l}\Delta \mathrm{T} \\
\text { gas }\end{array}$} & \multirow{3}{*}{$\begin{array}{l}\text { Required } \\
\text { cooling } \\
\text { amount }\end{array}$} & \multirow{3}{*}{$\begin{array}{l}\Delta \mathrm{T} \\
\text { water }\end{array}$} & \multicolumn{6}{|c|}{ Water cooling absorbed heat } & \multicolumn{2}{|c|}{$\begin{array}{l}\text { Other } \\
\text { cooling } \\
\text { amount }\end{array}$} \\
\hline & & & & \multicolumn{2}{|c|}{ Sensible heat } & \multicolumn{2}{|c|}{ Latent heat } & \multicolumn{2}{|l|}{ Total } & \multirow{2}{*}{$(\mathrm{kW})$} & \multirow{2}{*}{$\%$} \\
\hline & & & & $(\mathrm{kW})$ & $\%$ & $(\mathrm{~kW})$ & $\%$ & $(\mathrm{~kW})$ & $\%$ & & \\
\hline 1 & 493 & 80 & 32 & 32.2 & 41 & 45.9 & 58.7 & 78.1 & 97.5 & 2 & 2.4 \\
\hline 2 & 550 & 88 & 35 & 34.40 & 41.5 & 48.44 & 58.5 & 82.84 & 94 & 5.2 & 6 \\
\hline 3 & 660 & 106 & 45 & 37.78 & 37.5 & 62.86 & 62 & 100.6 & 95 & 5.4 & 5 \\
\hline 4 & 469 & 76 & 45 & 14.5 & 19.5 & 59.29 & 80.3 & 73.79 & 97 & 2.2 & 3 \\
\hline
\end{tabular}

For the P120 nozzle, the particle tracking figures by particle temperature, particle residence time, particle diameter, particle velocity magnitude, domain temperature, domain velocity magnitude, water vapor mass fraction, carbon dioxide mass fraction, and finally particle SMD distribution are shown through Fig.19 to Fig. 27 respectively.

\subsection{Comparison of Experimental Measurement and CFD Simulation}

The results of the experimental measurements and CFD simulation of the cooled EGT by the evaporative cooling system provided with the P120 nozzle are compared in Table 4. The values of the measured hot EGT, measured cooled EGT by the P120 nozzle and the simulated cooled EGT with the engine RPM starting from idle to maximum regime are demonstrated in one figure, Fig. 28.

\subsection{Discussion}

It is found that both the nozzle water flow rate and SMD representing the water sensible and latent heat respectively are affecting the cooling process together. Any of them cannot be considered the only responsible for the achieved cooling. The nozzle water flow rate and the nozzle SMD mutual effect could be interpreted instantaneously through the next equations.

$$
\begin{gathered}
\mathrm{Q}=\mathrm{h} * \mathrm{~A}_{\mathrm{t}} * \Delta \mathrm{T} \quad \mathrm{A}_{\mathrm{t}}=\text { No. of particles } * \mathrm{~A}_{\mathrm{p}}\left(\pi * \mathrm{~d}_{\mathrm{p}}{ }^{2}\right) \\
\text { No. of particles }=\frac{\dot{\mathrm{m}}_{\mathrm{w}}}{\text { one particle mass }\left(\rho * \frac{\pi}{6} * \mathrm{~d}_{\mathrm{p}}{ }^{3}\right)} \\
\mathrm{Q}=6 * \mathrm{~h} * \frac{\dot{\mathrm{m}}_{\mathrm{w}}}{\rho * \mathrm{~d}_{\mathrm{p}}} * \Delta \mathrm{T}
\end{gathered}
$$

\begin{tabular}{|c|c|c|c|c|c|}
\hline \multirow{3}{*}{ No. } & \multirow{3}{*}{$\mathrm{RPM}$} & \multicolumn{3}{|c|}{ EGT $\left({ }^{\circ} \mathrm{C}\right)$} & \multirow{3}{*}{$\begin{array}{l}\text { Deviation } \\
\%\end{array}$} \\
\hline & & \multirow{2}{*}{$\begin{array}{l}\text { Before } \\
\text { cooling }\end{array}$} & \multicolumn{2}{|l|}{ After cooling } & \\
\hline & & & Experimental & CFD & \\
\hline 1 & 50000 & 480 & - & 53 & - \\
\hline 2 & 60000 & 482 & - & 53 & - \\
\hline 3 & 70000 & 487 & - & 54 & - \\
\hline 4 & 80000 & 490 & - & 54 & - \\
\hline 5 & 90000 & 494 & - & 55 & - \\
\hline 6 & 10000 & 500 & - & 56 & - \\
\hline 7 & 120000 & 550 & 50 & 57 & 1.4 \\
\hline 8 & 140000 & 610 & 53 & 60 & 1.3 \\
\hline 9 & 165000 & 730 & 64 & 70 & 1 \\
\hline
\end{tabular}

Table 4. Comparison of experimental and CFD simulation for cooled EGT 
Increasing the total water flow rate means increasing the total number of particles which turns on increasing the total particle surface area across which heat transferred from the hot gas to the droplets i.e. increasing the cooling rate through sensible heat. The inverse relation between total heat transfer rate and the nozzle SMD is clear so the less nozzle SMD, the higher cooling rate through latent heat.

In the real conditions, the hot exhaust gas is cooled through different mechanisms:

- The expansion inside the quench chamber as the quench zone has a larger diameter than inlet piping system.

- The heat transferred by convection from hot gas to droplet (the only considered when solving the two-phase flow coupling between the continuous and dispersed phase heat transfer problem including the water sensible and latent heat effect).

- Heat transferred by conduction through the chamber walls from inside the quench chamber to the surrounding.

- Heat transferred by convection and radiation from the chamber walls to the surrounding. The radiation effect can be neglected due to its relatively low contribution.

The anticipated contributions for these mechanisms in the total temperature difference are demonstrated through the Pie configuration shown in Fig. 29. The accurate measurement of such values is a very complex task as it requires special measurement installations. Moreover, precise sensors will be a must. The presented evaporative cooling design approach facilitates the problem based on the cooling system walls adiabatic assumption i.e. all heat will be drawn through the cooling water. For an optimum design, the heat drawn through water latent heat should be dominant.

\section{Conclusions and Future Work}

Evaporative cooling is considered the best method for cooling the gas turbines hot exhaust gas since the evaporation of water extracts a large amount of heat. In this paper, a conceptual and design approaches for an efficient cooling system provided by water spray configuration are introduced. The selection and sizing of spray nozzles are the most important decisions in the introduced approach. Drop size (nozzle SMD), water pressure drop, nozzle orifice size (affecting nozzle flow rate), and spray angle are critical design factors.

A systematic evaluation for predicting the evaporative cooling performance using CFD simulation is also demonstrated. The evaluation is based on a sensitivity analysis and verified with experimental measurements. The Lagrangian-Eulerian (3D steady RANS) technique, in spite of its limitations, can accurately predict the evaporation cooling process with an acceptable accuracy. The average deviation for the cooled exhaust gas temperature is less than $1.2 \%$. The impact of the quench chamber inlet piping diameter, inlet hot gas temperature for the continuous phase and the nozzle water flow rate, SMD for the discrete phase are also investigated and it is demonstrated that the selection of these parameters is very important for reliable design.

\section{Future Work}

- Evaporative cooling performance optimization using some optimization techniques.

- Evaporative cooling performance investigation using Particle Image Velocimetry (PIV) technique in a transparent quench chamber. 


\section{References}

[1] Viggo Westergaard and James A. Fi Fe, "Flue gas cooling”,Boston, Massachusetts.

[2] Sjenitzer, F., "The evaporation of a liquid spray injected into a stream of gas", Chemical Engineering Science, 17, 1962, pp. 309-322.

[3] "Multiphase flow handbook".

[4] Subramaniam S., "Lagrangian-Eulerian methods for multiphase flows", Prog Energy Combust Sci, 2013.

[5] Bird, R.B., Stewart, W.E. and Lightfoot, E.N., "Transport Phenomena", New York, 1960.

[6] Karl A, Frohn A., "Experimental investigation of interaction processes between droplets and hot walls", Phys Fluids, 2000.

[7] John A. Danielson, "Air pollution engineering manual”, second edition.

[8] "Method and apparatus for quenching hot flue gases", United States Patent, Nov. 21, 2000.

[9] Frohn A, Roth N., "Dynamics of droplets", Springer, 2000

[10] "Spray gas quench design considerations", BETE fog nozzle handbook

[11] Pagcatipunan, C., Schick, R., "Maximize the Performance of Spray Nozzle Systems", Chemical Engineering Progress, December 2005.

[12] Sovani SD, Sojka PE, Sivathanu YR. "Prediction of drop size distribution from first principles", 2000

[13] Ranz W.E. and Marshall, W.R. Jr., "Evaporation from drops", Part I, Chemical Engineering Progress, 1952, pp. $141-146$.

[14] Markus J. S. and Paul-Strähle, "CFD analysis of gas cooling”, ILASS-Americas, $20^{\text {th }}$ Annual Conference on Liquid Atomization and Spray Systems, Chicago, IL, May 2007.

[15] Ashgriz N., "Handbook of atomization and sprays", Springer, 2011.

[16] Charles W. Lipp, Thomas J. Kling and C. P. Christenson, "A fresh look at design of spray gas quench systems", ILASS-Americas, $21^{\text {th }}$ Annual Conference on Liquid Atomization and Spray Systems, Orlando, Florida, May 2008.

[17] Liu, H., Wiliam \& Andrew, "Science and Engineering of Droplets", 2000.

[18] Morsi SA, Alexander AJ., "An investigation of particle trajectories in two-phase flow systems", Fluid Mech, 1972.

[19] ANSYS Fluent 16, www.fluent.com, 2016.

[20] Oakley, D.; Bahu, R. and Reay, D., "The Aerodynamics of Co-current Spray Dryers, Amsterdam, 1992”, pp. 359-364. 


\section{Figures}

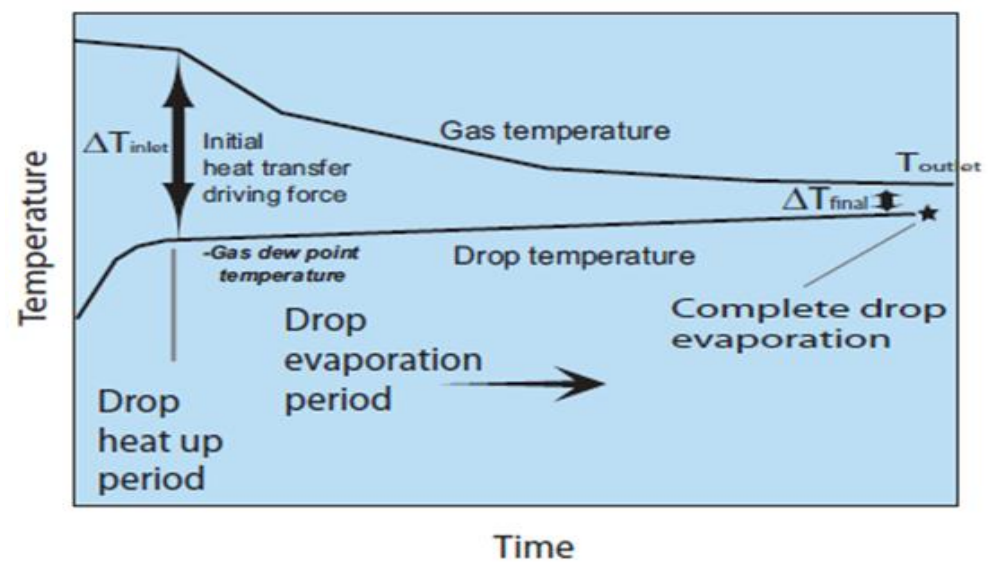

Fig. 1. Temperature profile

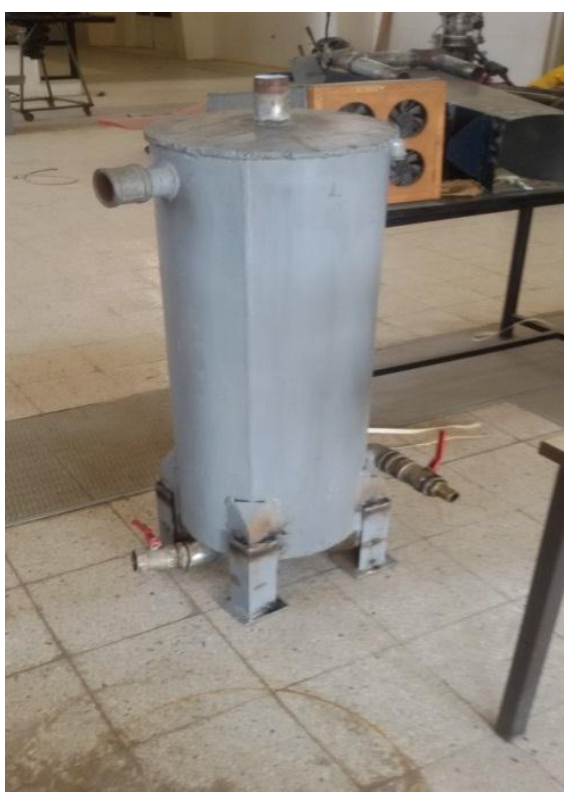

(a)

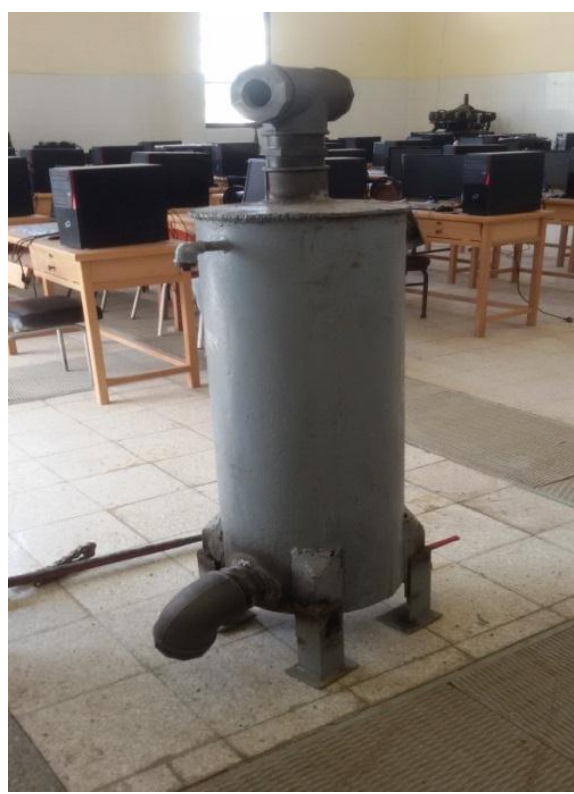

(b)

Fig. 2. (a) 2" inlet and outlet piping quench chamber, (b) Final quench chamber

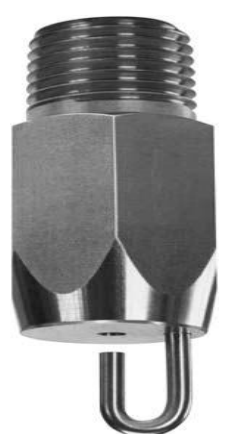

(a)

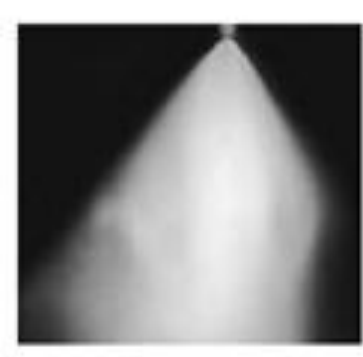

Fog

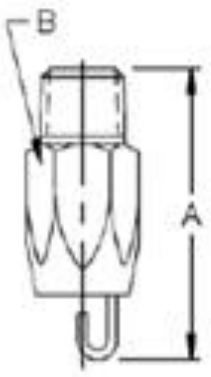

Male

(b)

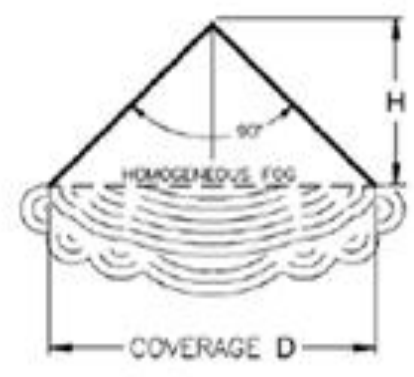

F $\propto$ P Pattern

Fig. 3 (a). BETE $P$ series nozzles, (b) Nozzle fog pattern 


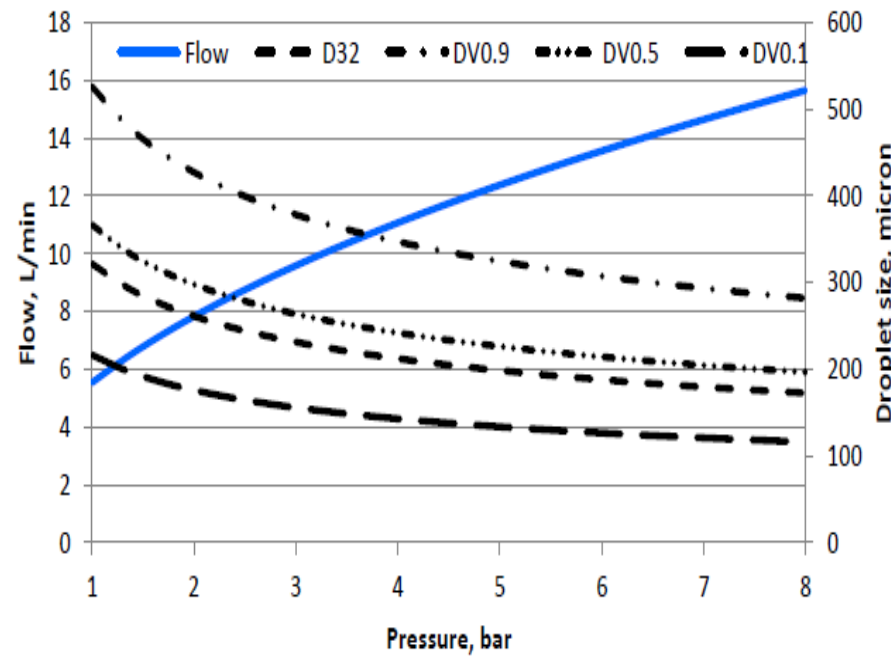

(a)

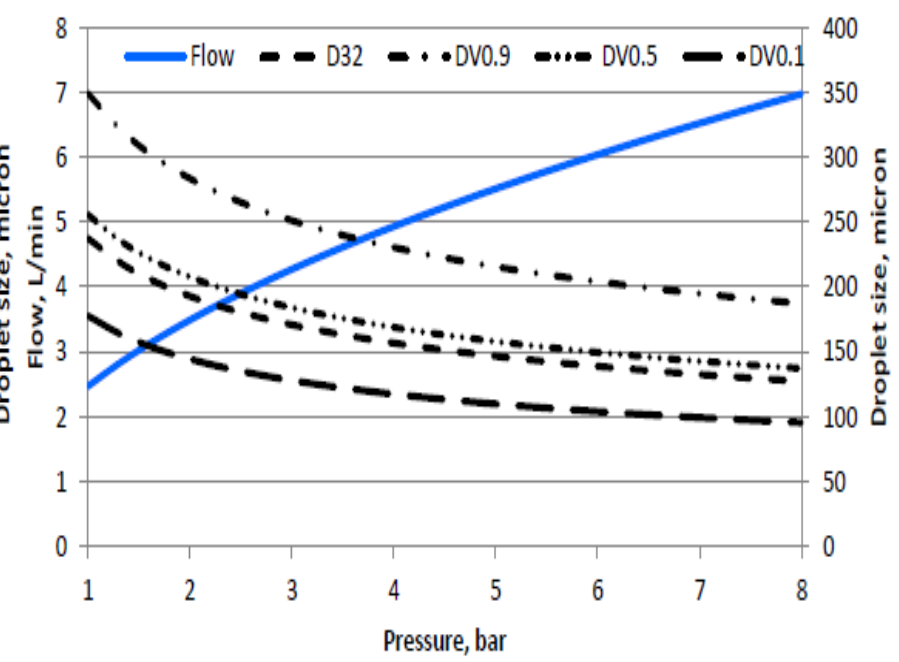

(b)

Fig. 4 (a). P120 nozzle characteristic curve, (b) P80 nozzle characteristic curve

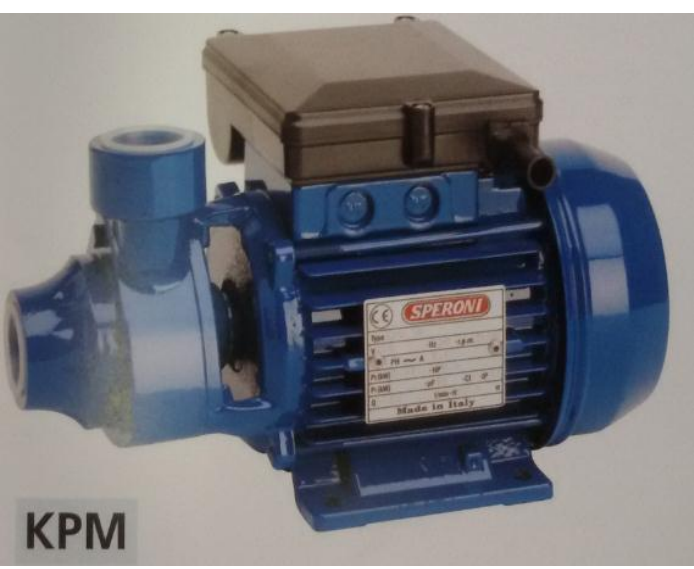

(a)

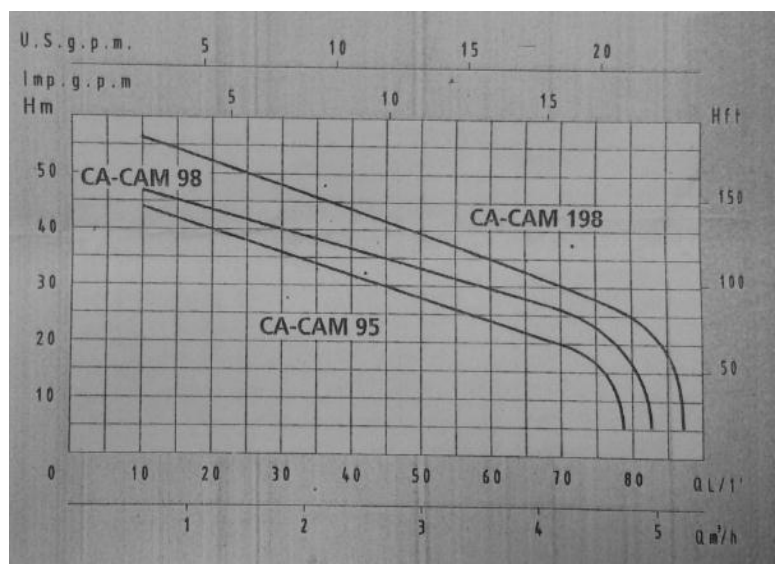

(b)

Fig. 5 (a) Speroni CAM198 water pump, (b) Pump characteristic curve

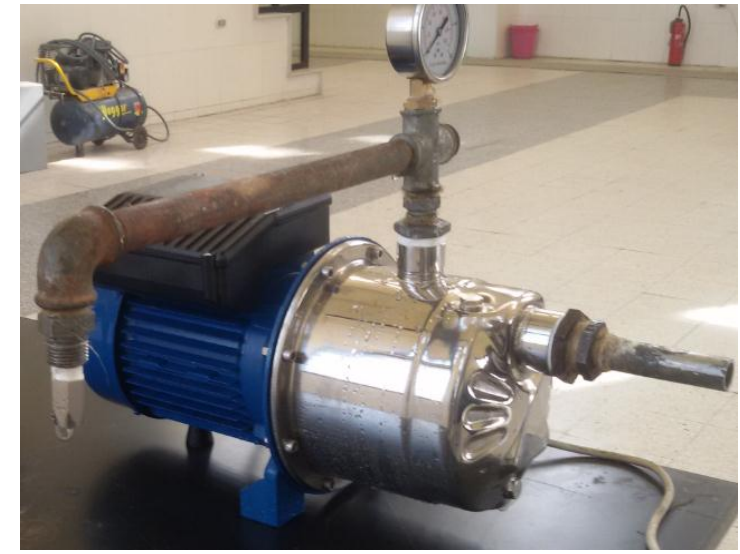

(a)

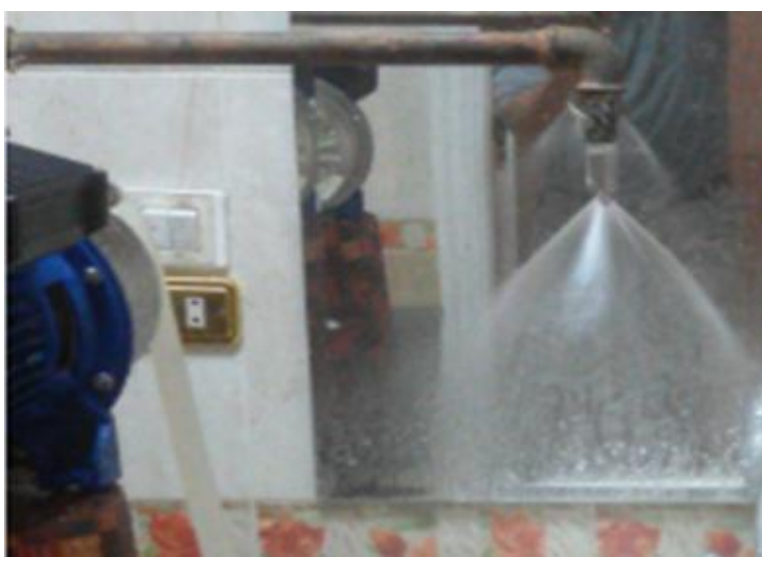

(b)

Fig. 6 (a) Pump-nozzle installation, (b) Tested nozzle fog pattern 


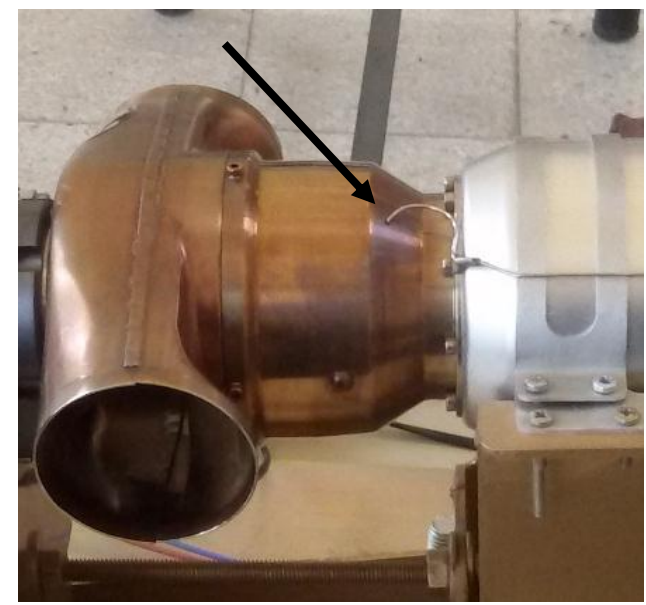

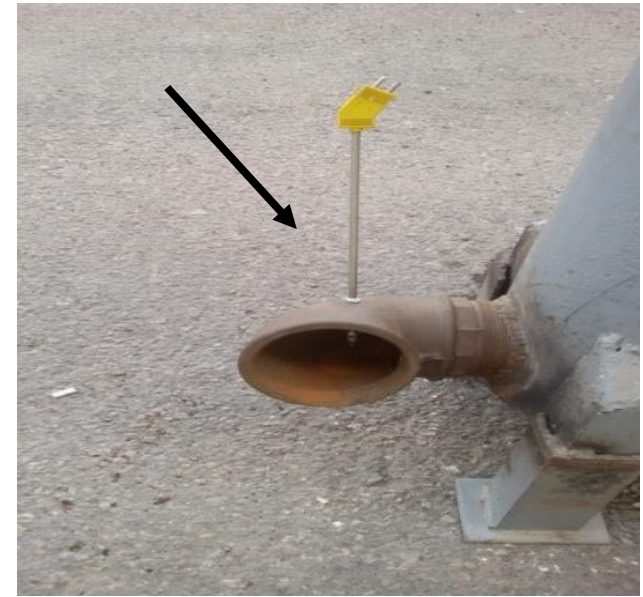

(b)

Fig. 7 (a) Hot gas thermocouple position, (b) Cooled gas thermocouple position

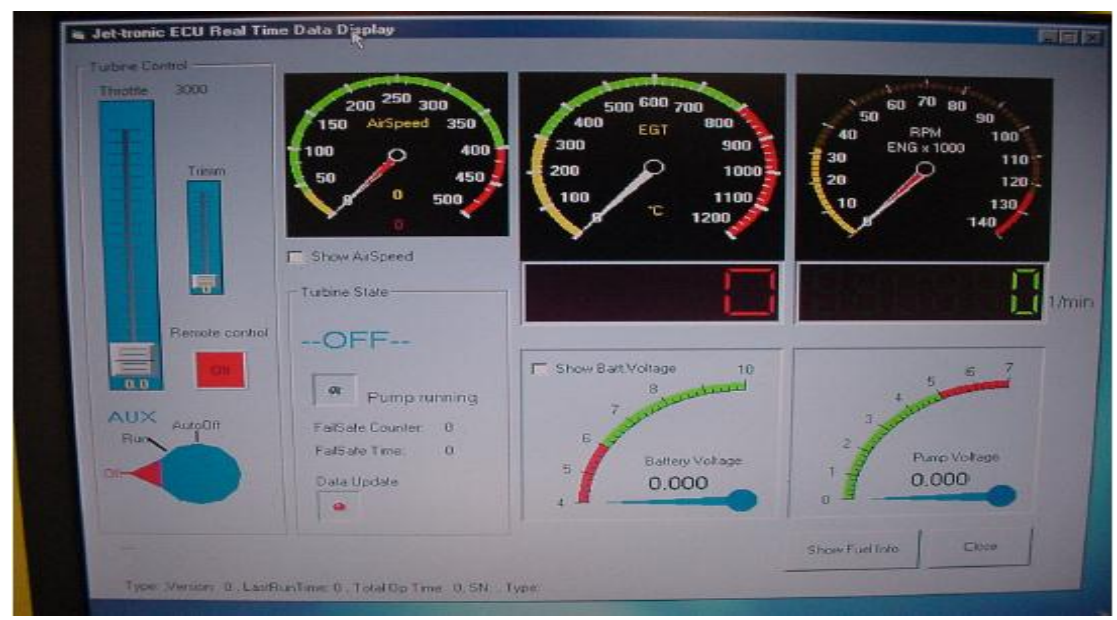

Fig. 8. Engine control panel screen

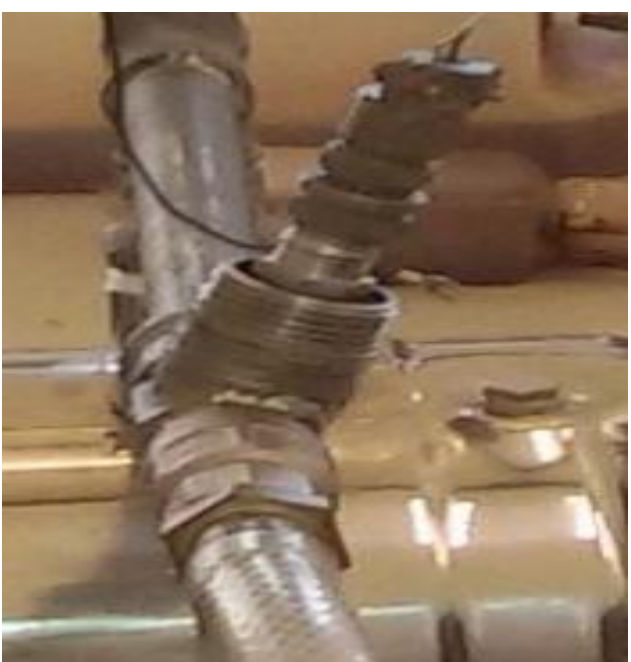

(a)

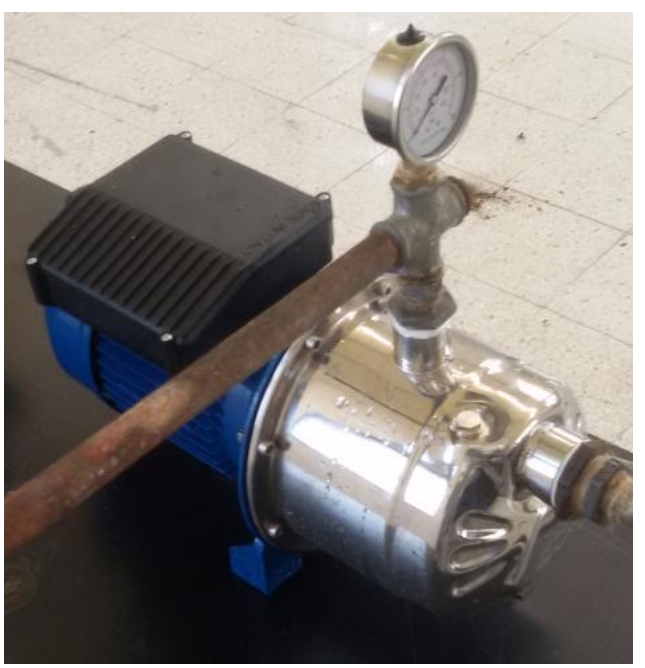

(b)

Fig. 9 (a) Omega FTP turbine meter, (b) Water pressure gauge 


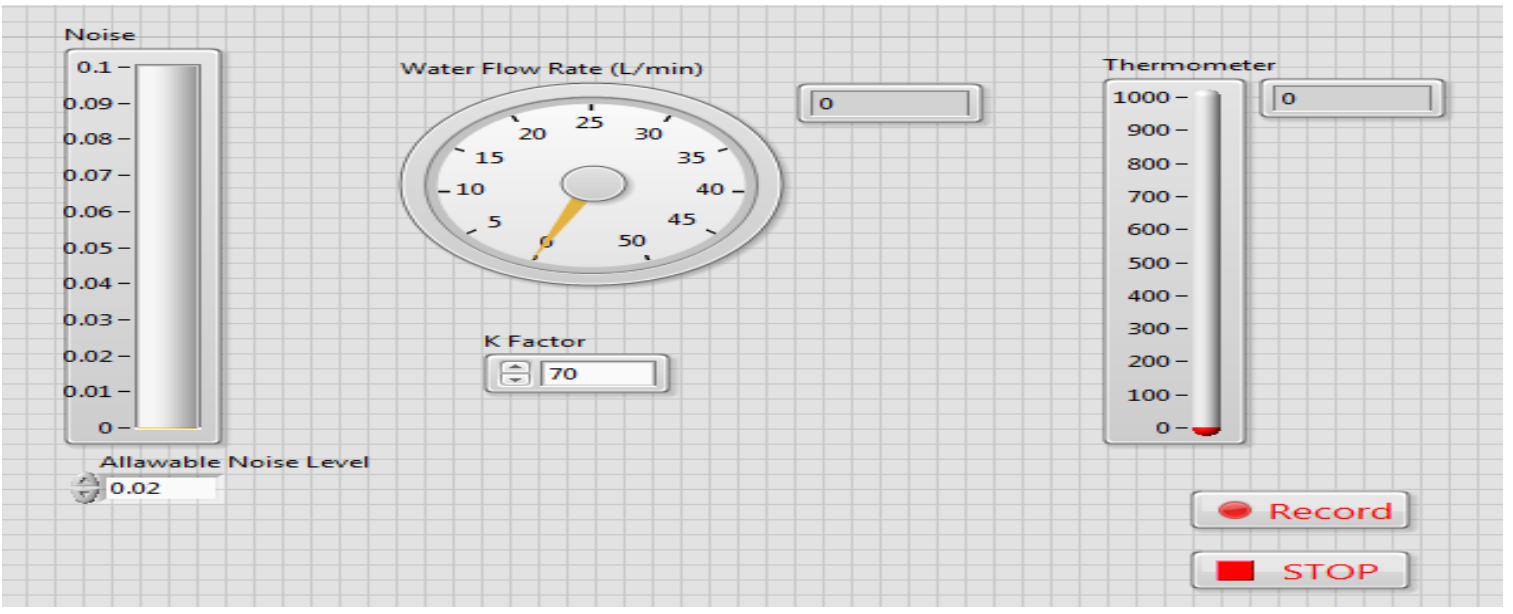

Fig. 10. Labview monitoring interface

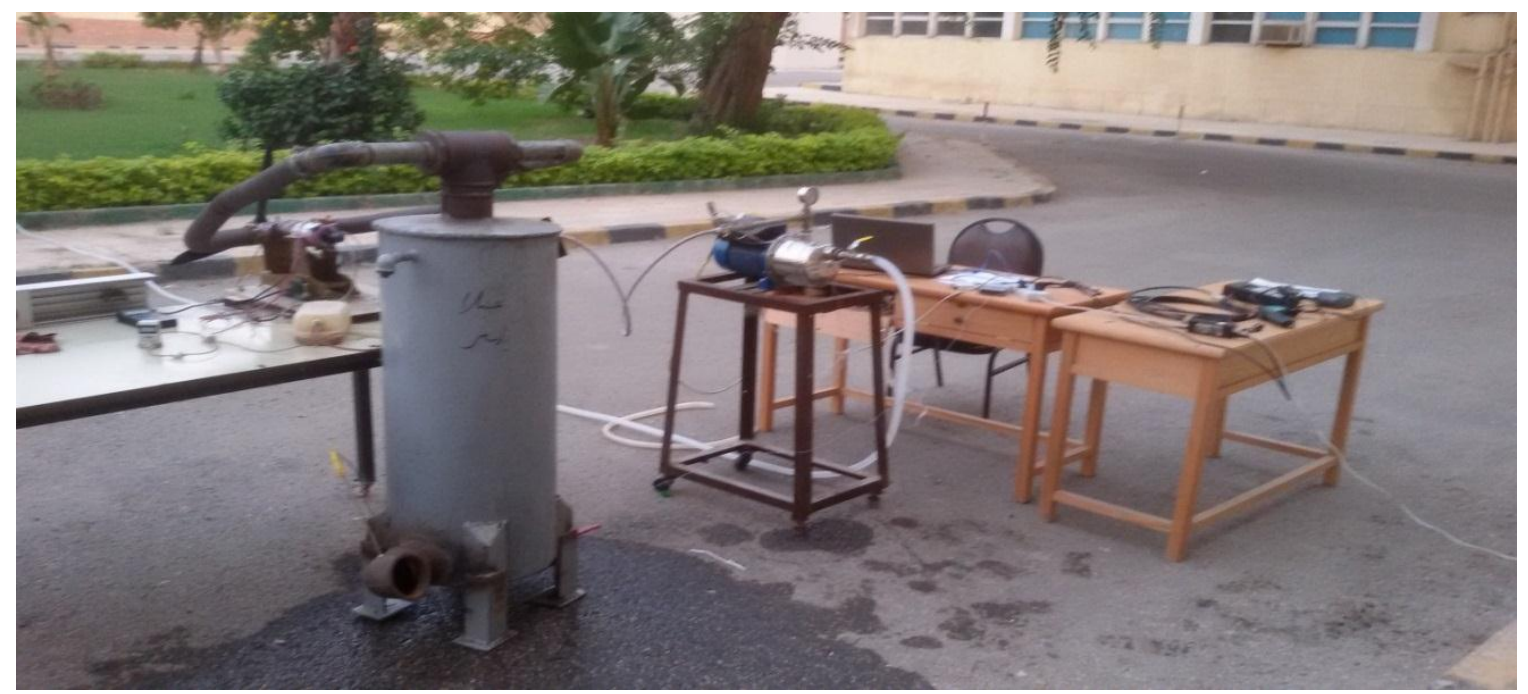

Fig. 11. Complete test rig view

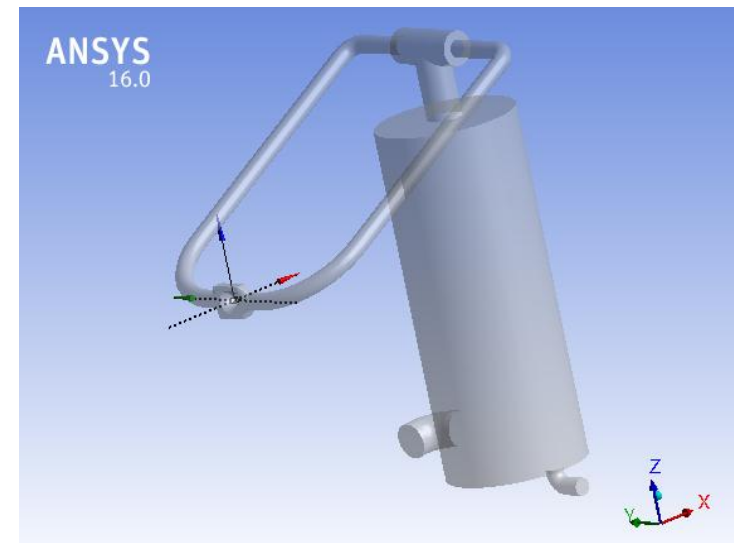

(a)

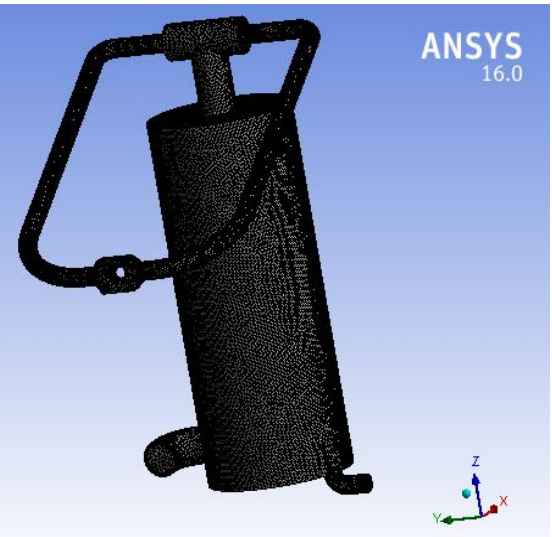

(b)

Fig. 12 (a) 3D CAD model, (b) computational grid (1,407,374 cells) 


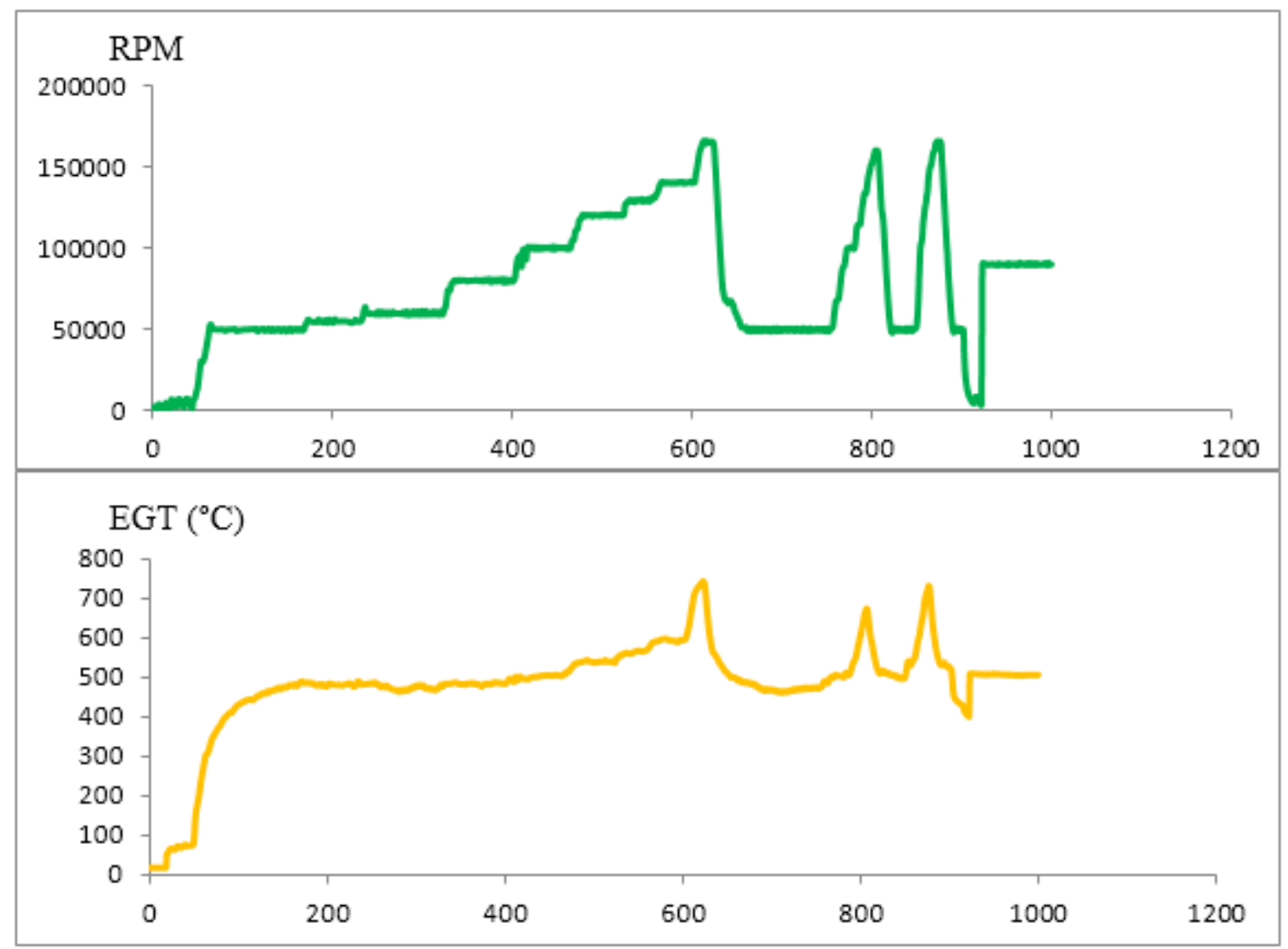

Fig. 13. Hot EGT vs RPM

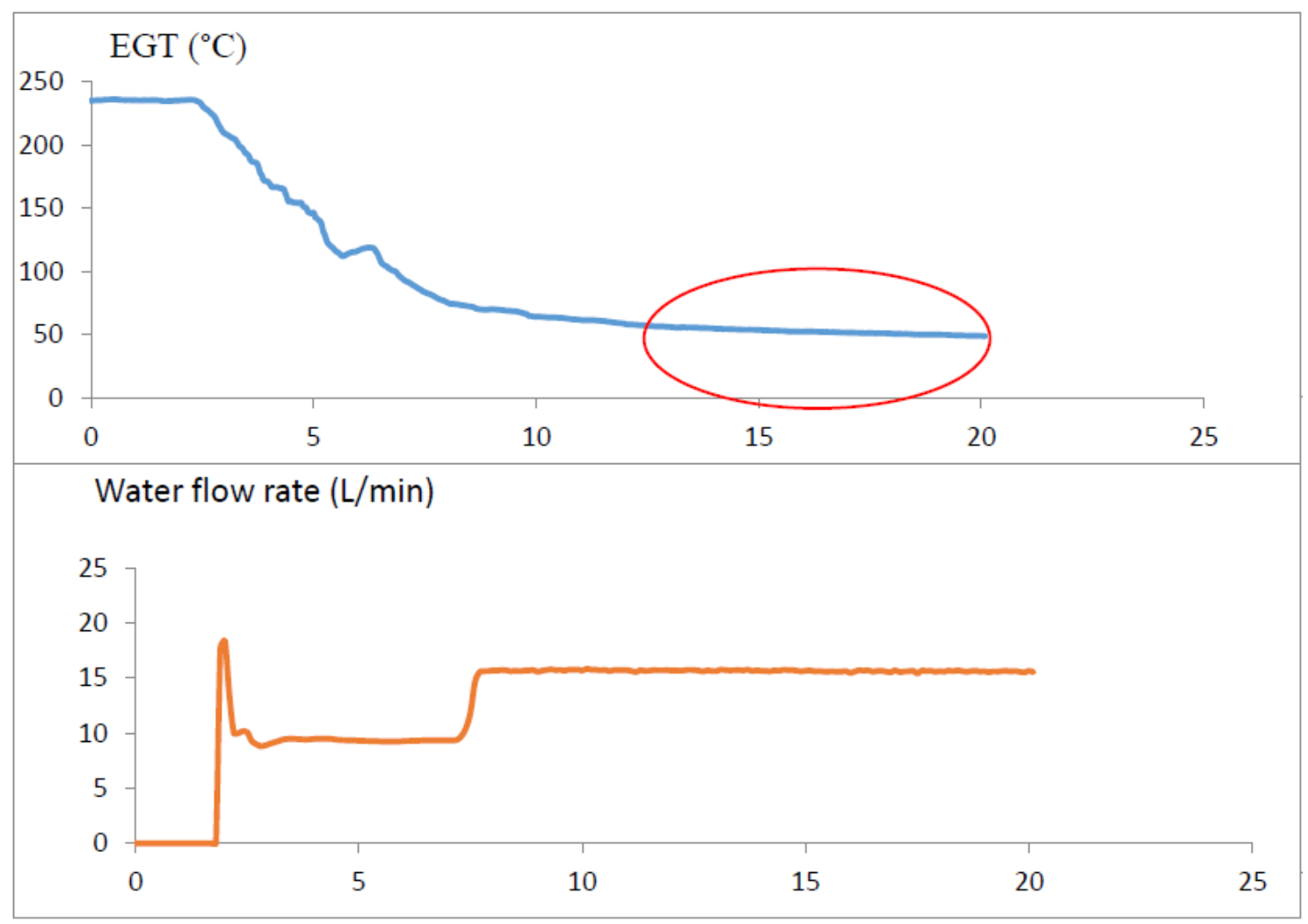

Fig. 14 a. Cooled exhaust gas profile for maximum water rate at $120000 \mathrm{rpm}$ 


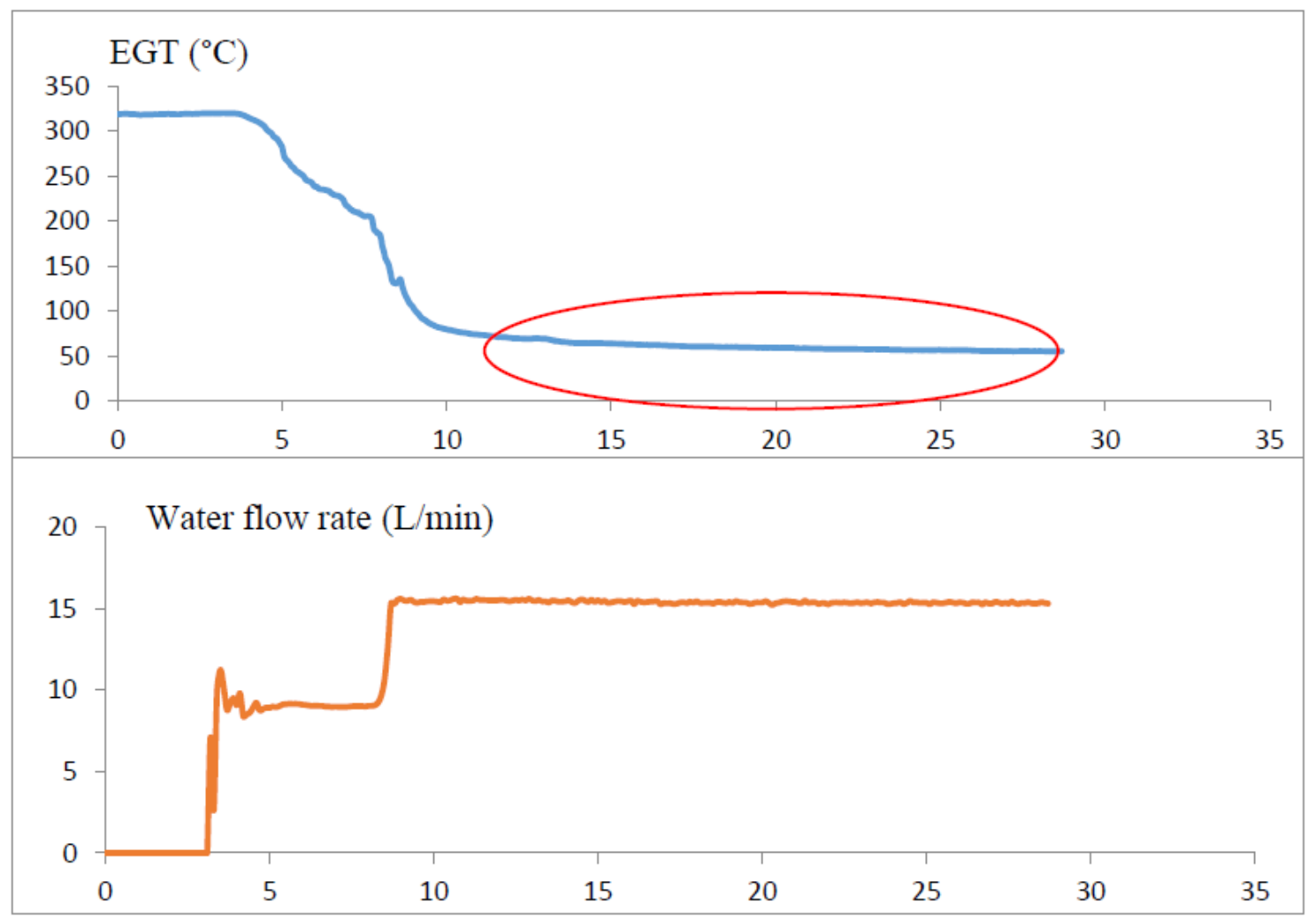

Fig. 14 b. Cooled exhaust gas profile for maximum water rate at $140000 \mathrm{rpm}$

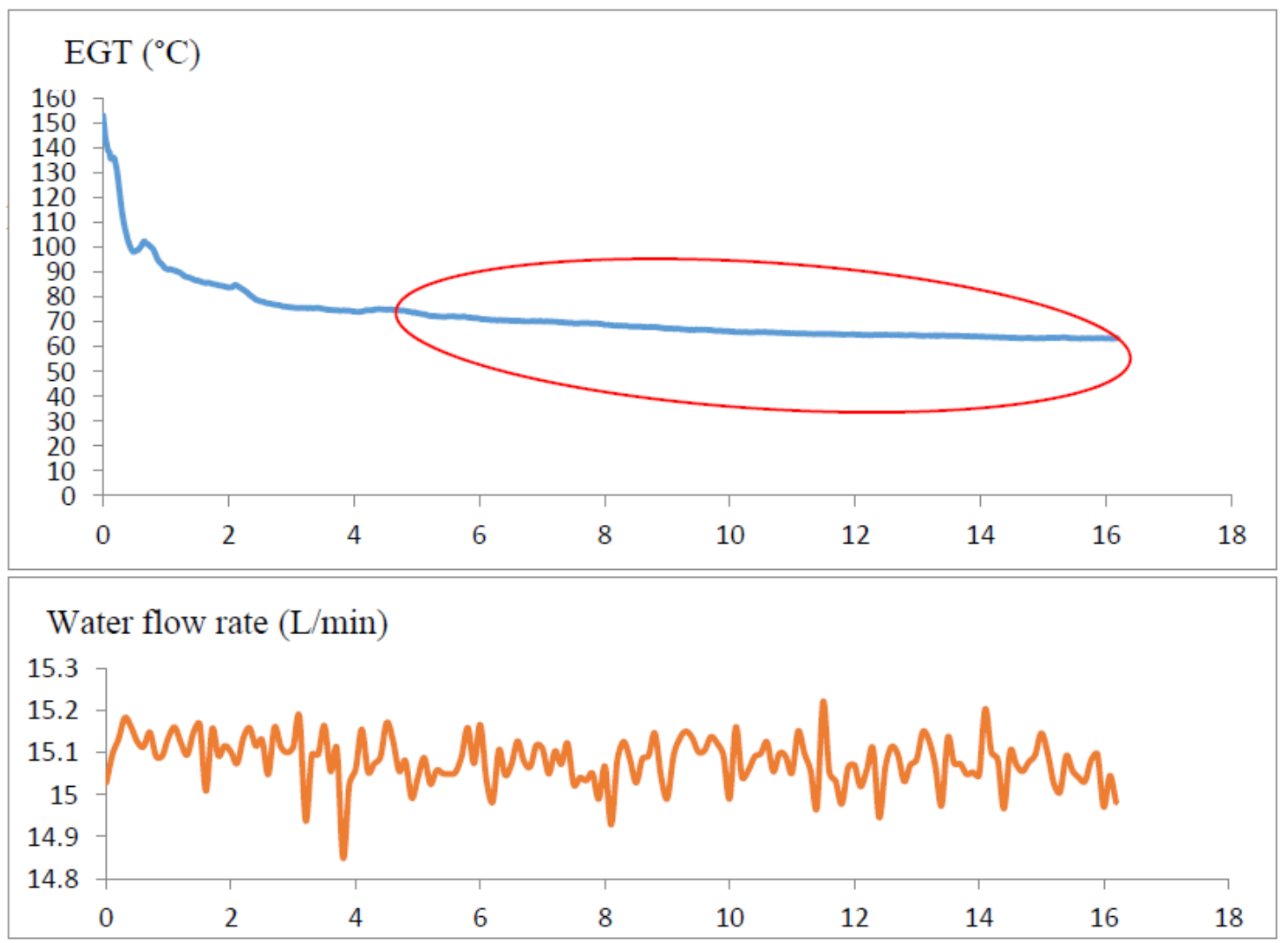

Fig. 14 c. Cooled exhaust gas profile for maximum water rate at $165000 \mathrm{rpm}$ 


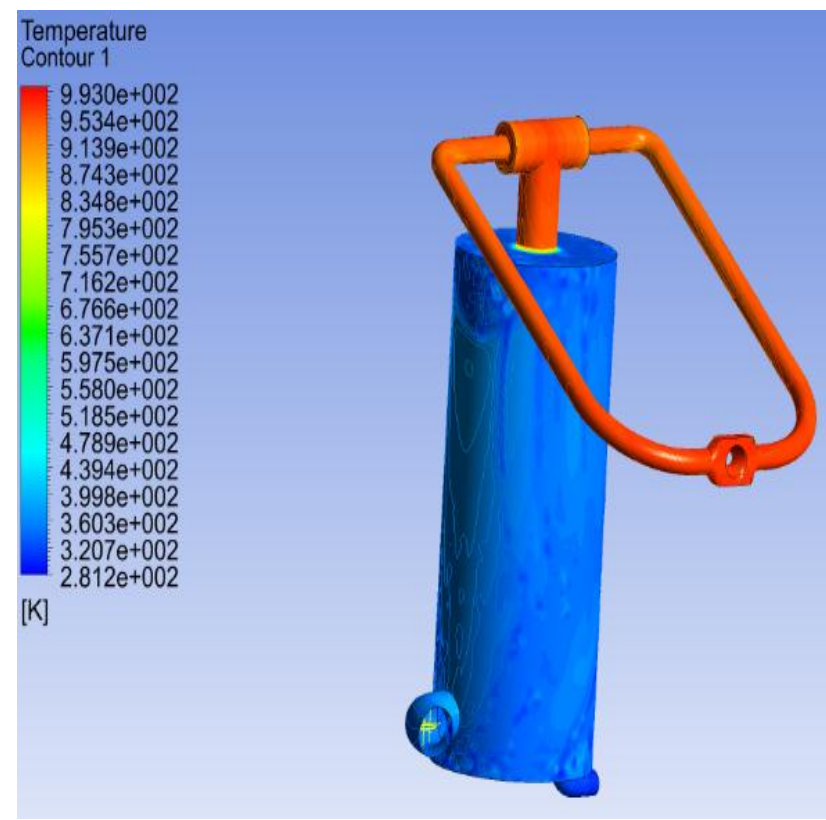

(a)

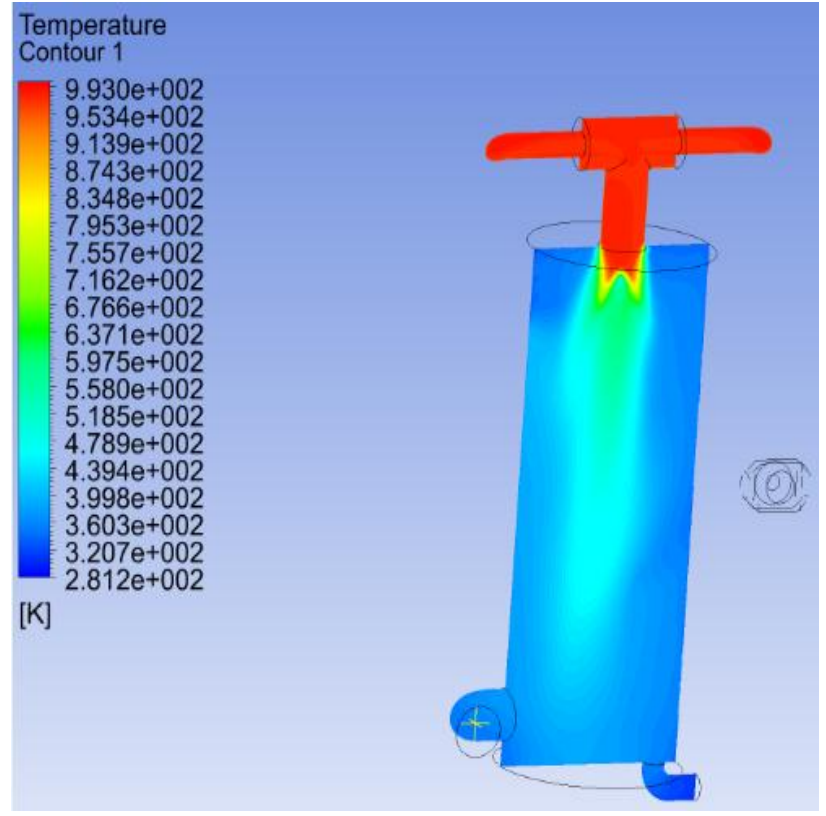

(b)

Fig. 15 (a) Temperature distribution at all domain, (b) At mid half plane

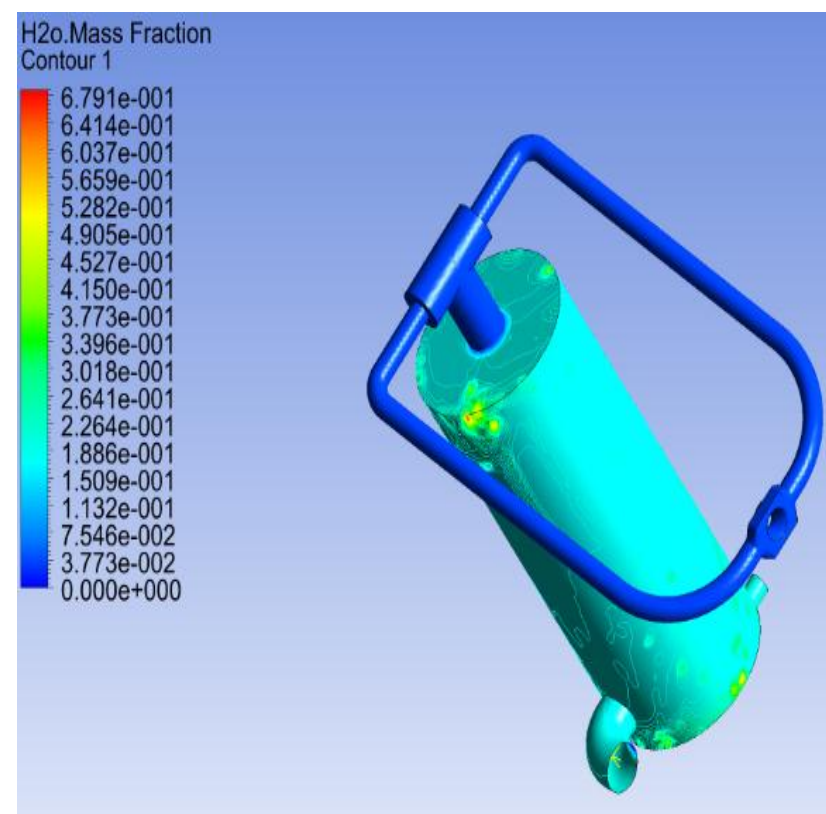

(a)

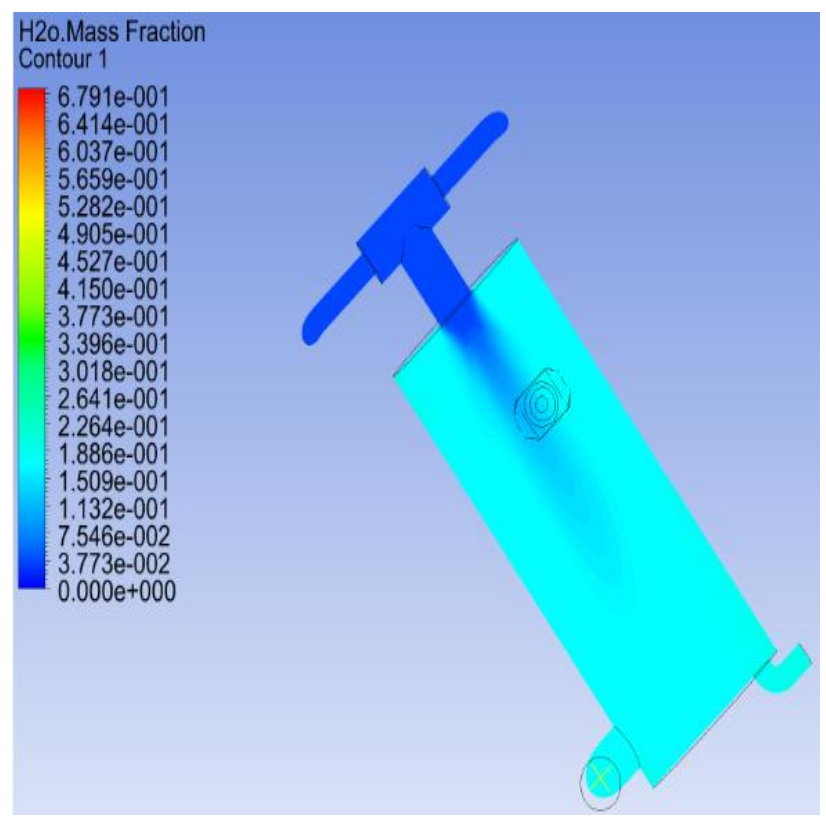

(b)

Fig. 16 (a) $\mathrm{H}_{2} \mathrm{O}$ mass fraction distribution at all domain, (b) At mid half plane 


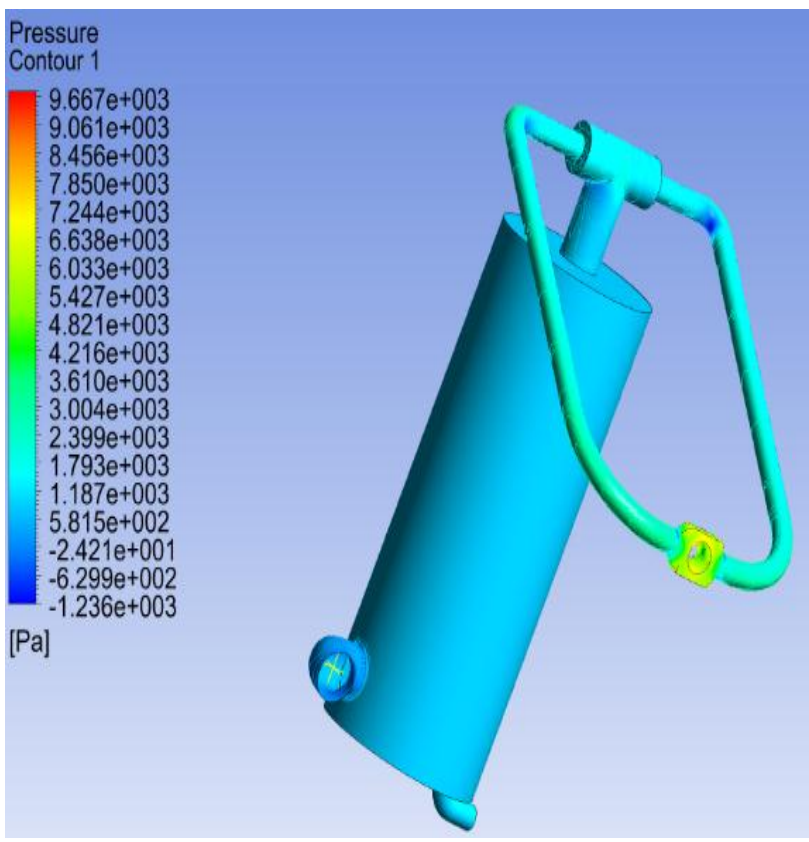

(a)

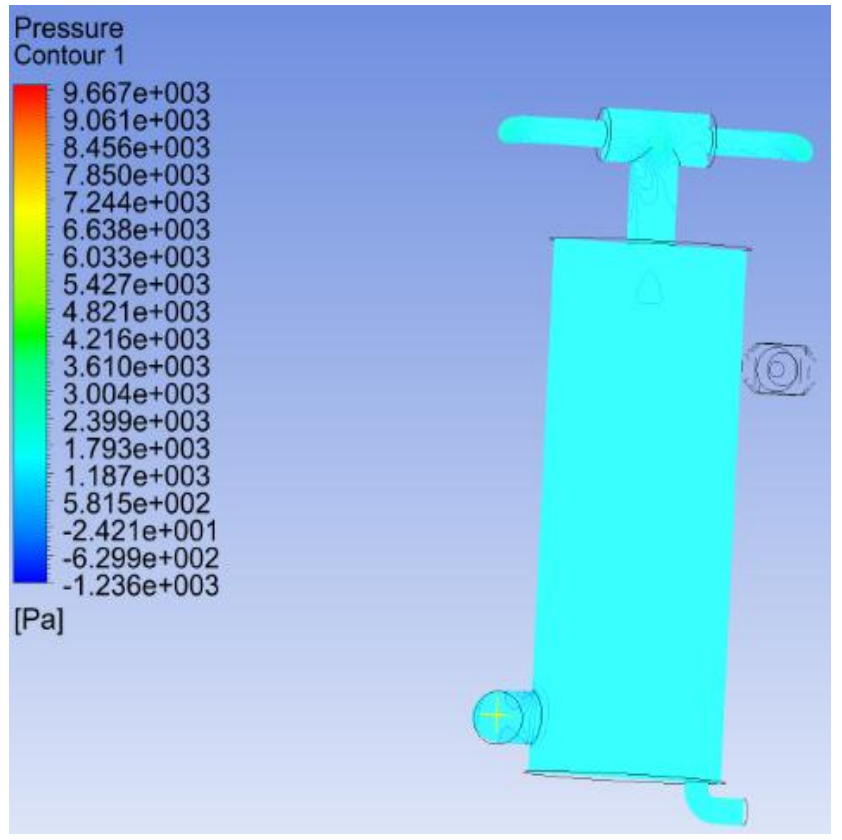

(b)

Fig. 17 (a) Pressure distribution at all domain, (b) At mid half plane

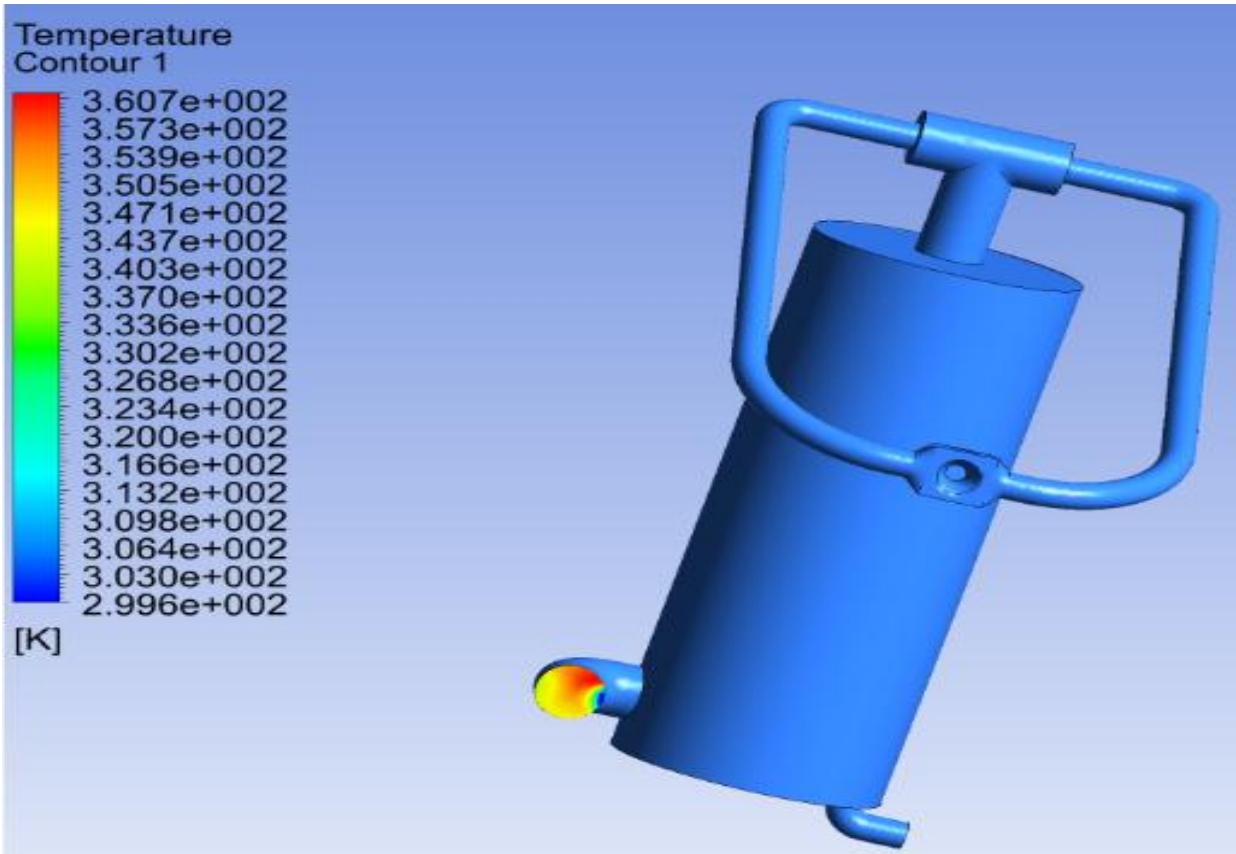

Fig. 18. Temperature distribution at quench chamber exit elbow 


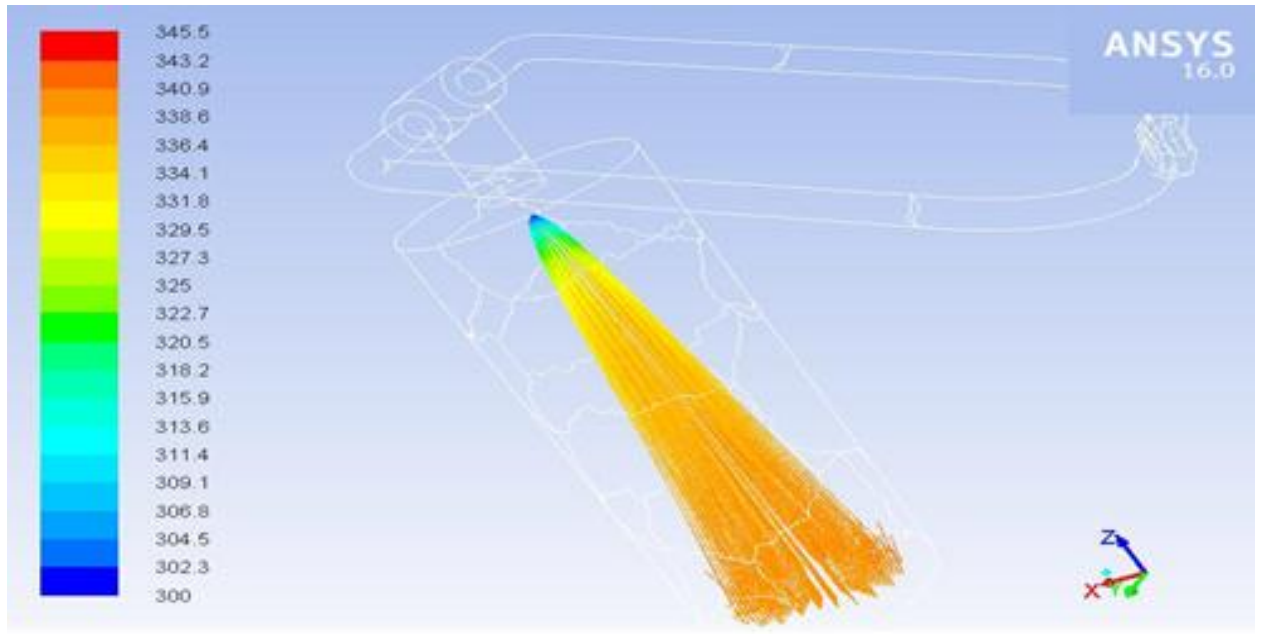

Fig. 19. Particle tracking by particle temperature

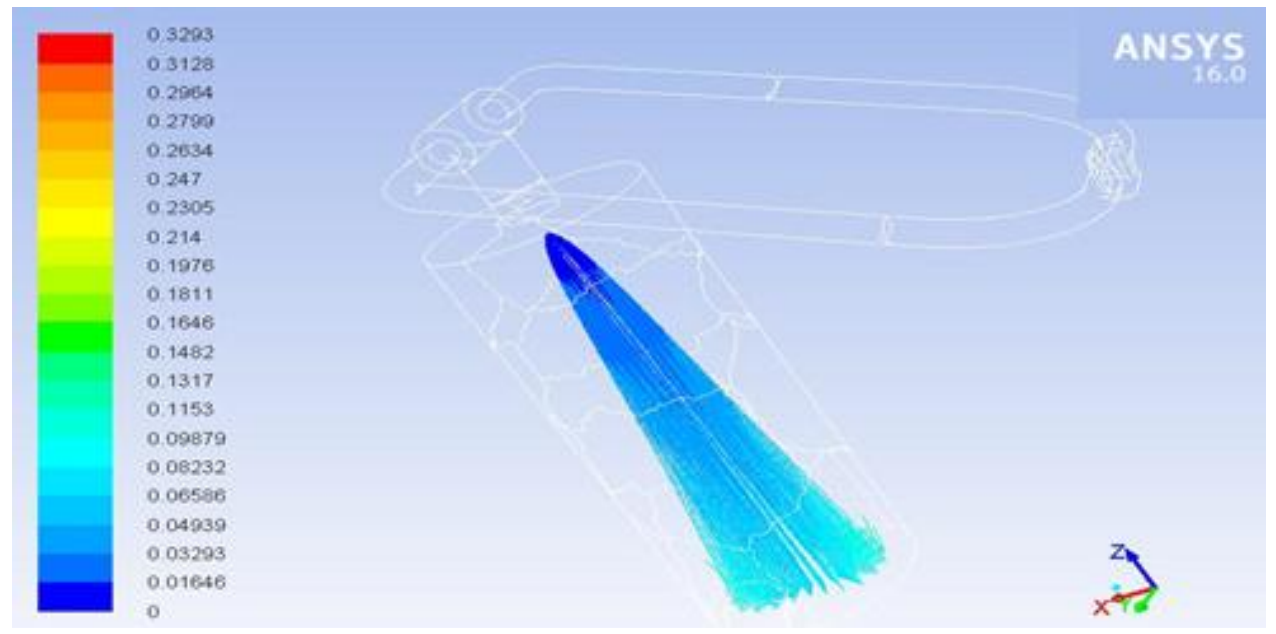

Fig. 20. Particle tracking by particle residence time

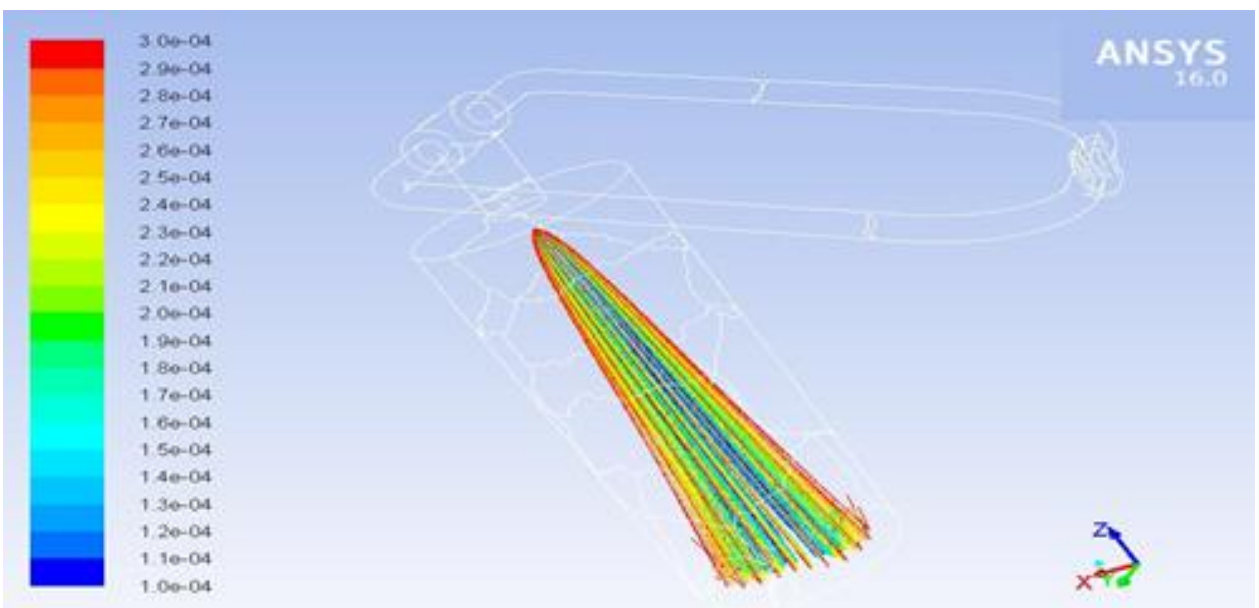

Fig. 21. Particle tracking by particle diameter 


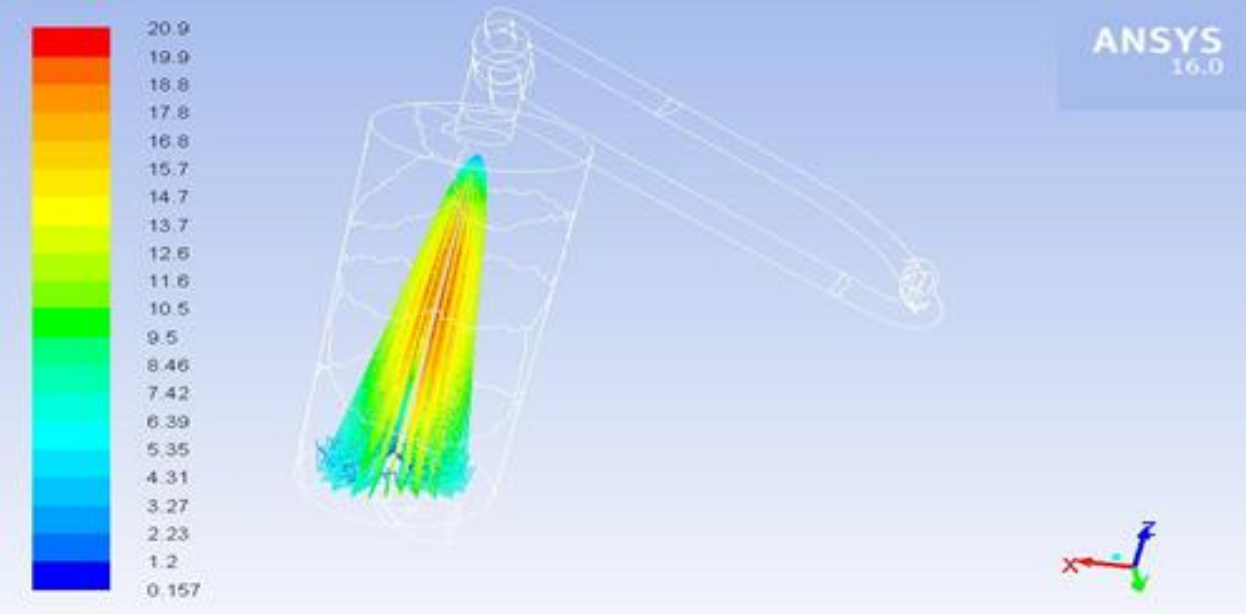

Fig. 22. Particle tracking by particle velocity

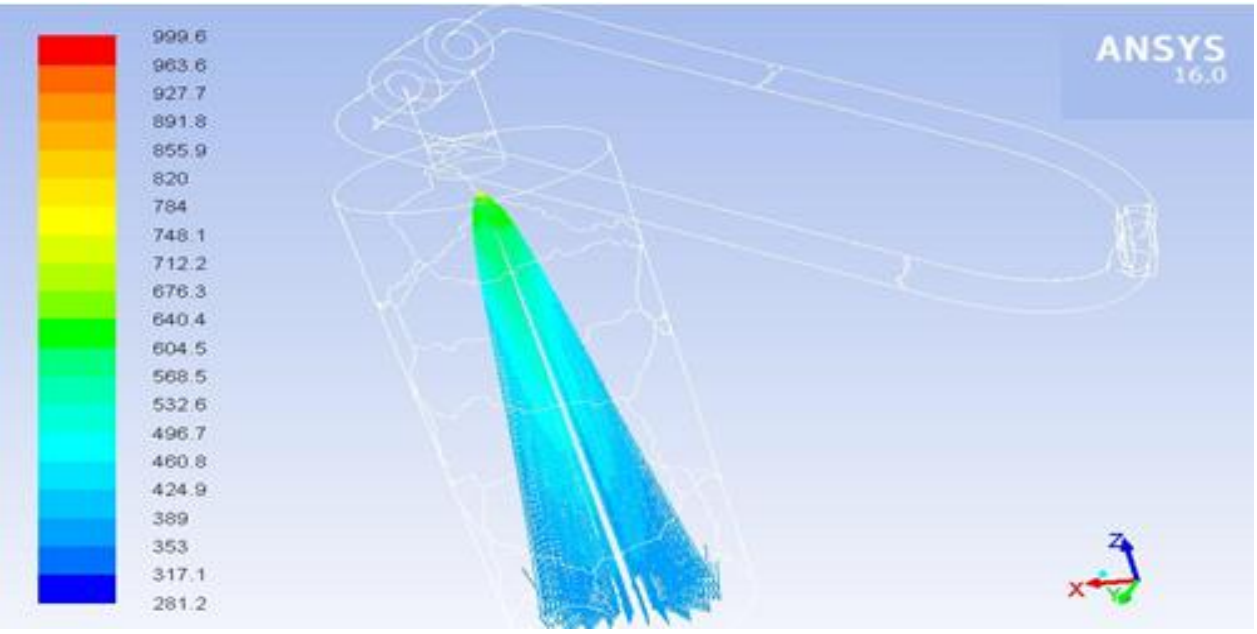

Fig. 23. Particle tracking by domain temperature

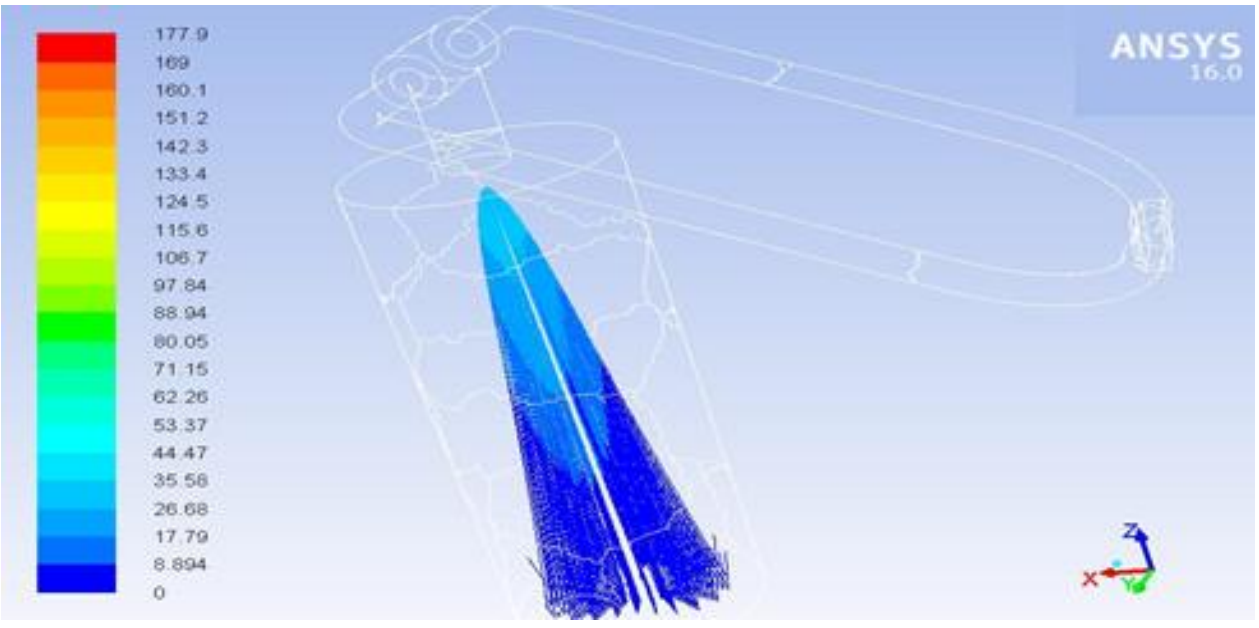

Fig. 24. Particle tracking by domain velocity 


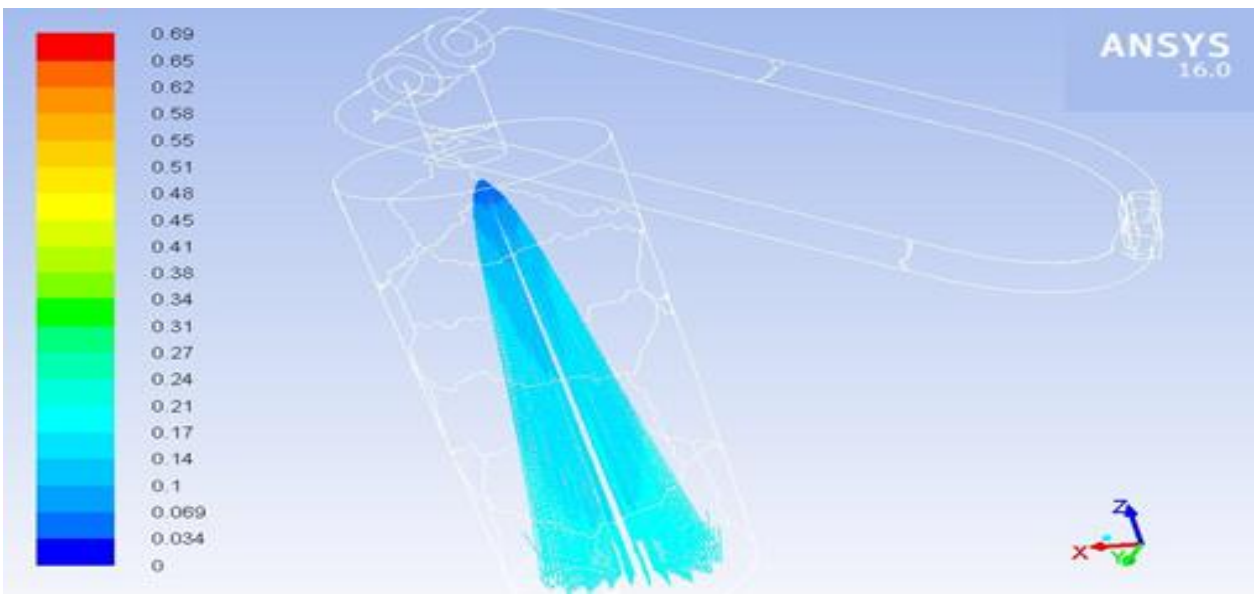

Fig. 25. Particle tracking by $\mathrm{H}_{2} \mathrm{O}$ mass fraction

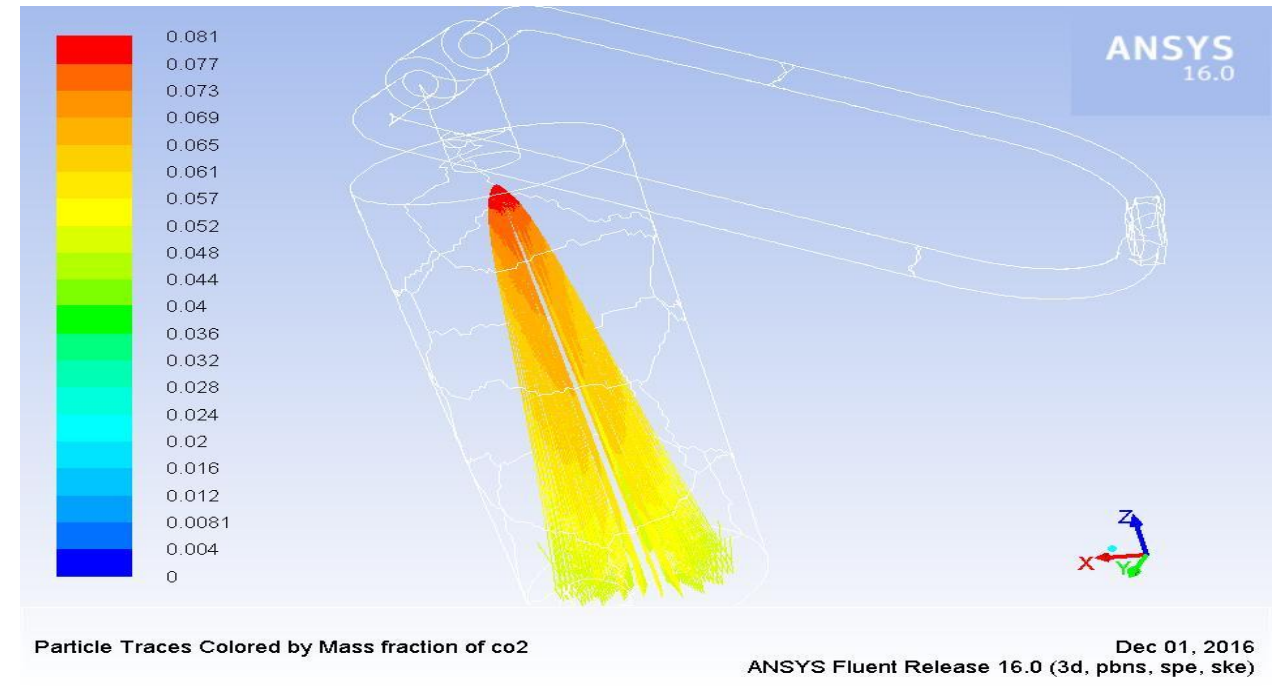

Fig. 26. Particle tracking by $\mathrm{CO}_{2}$ mass fraction

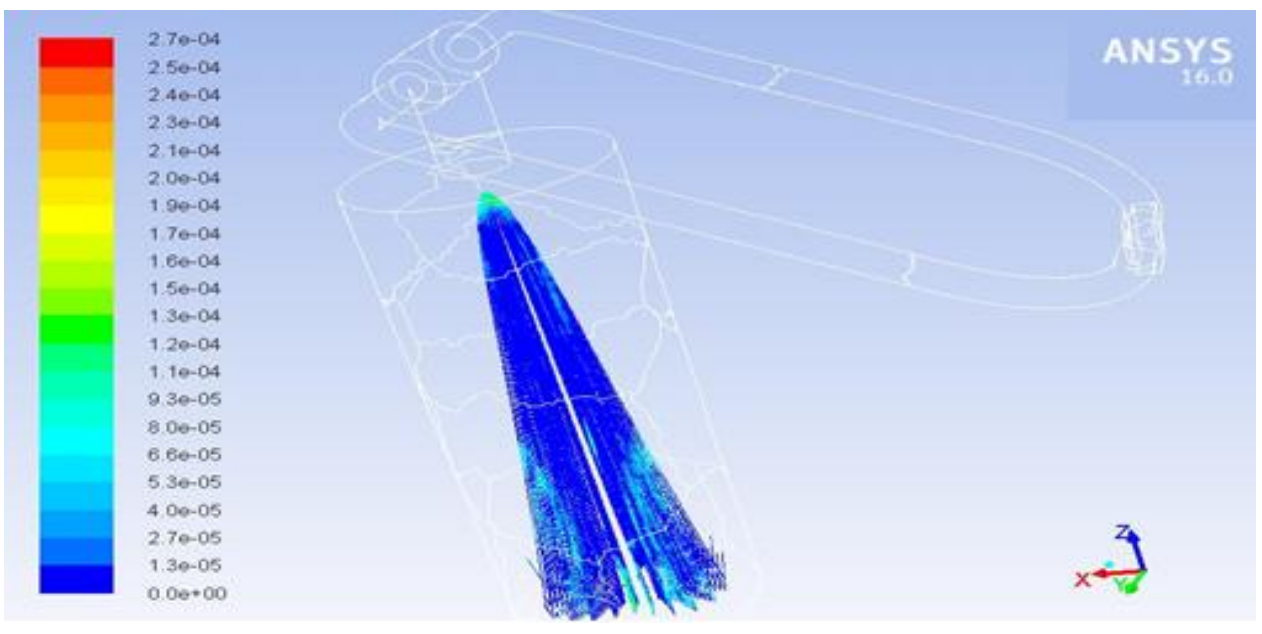

Fig. 27. Particle tracking by particle SMD distribution 
- Experimental cooled EGT $\rightarrow-$ CFD cooled EGT - - Experimental hot EGT

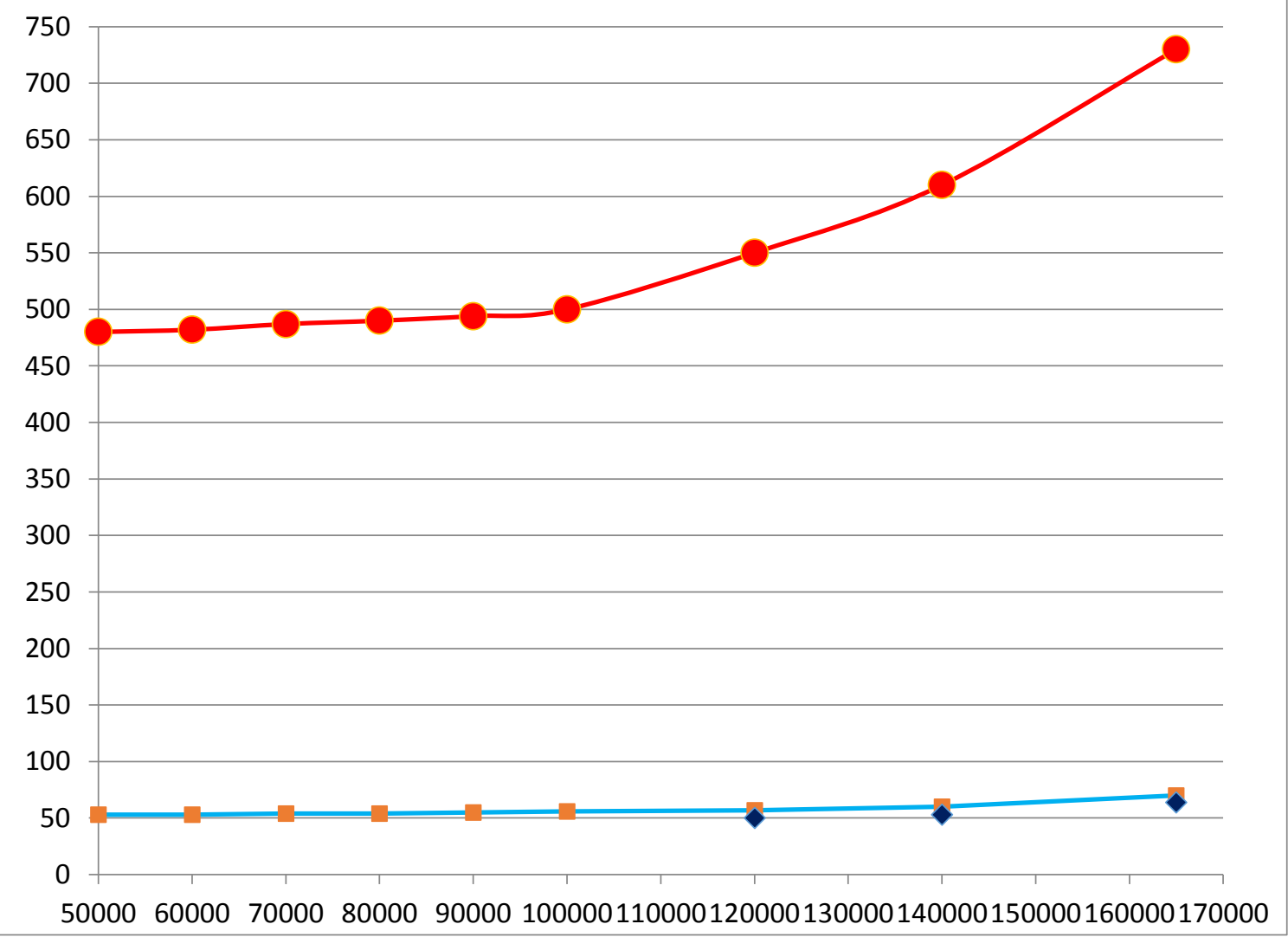

Fig. 28. Experimental hot, cooled EGT and CFD cooled EGT with engine RPM

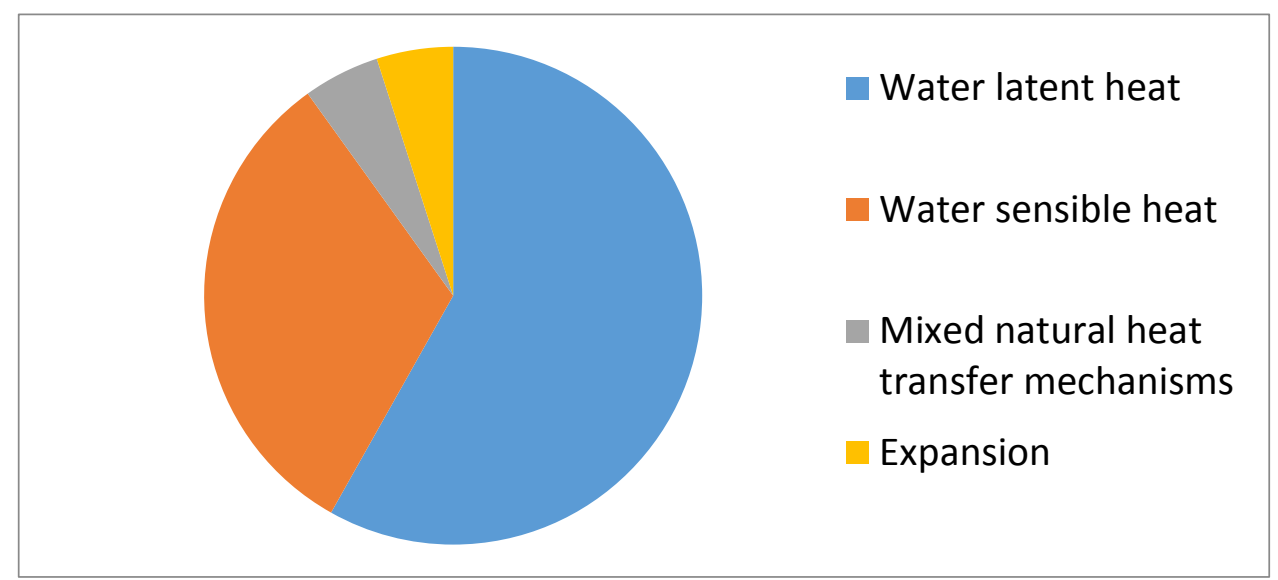

Fig. 29. Different heat transfer mechanisms Pie chart 